Research

Elsevier Editorial system(tm) for Fisheries

Manuscript Draft

Manuscript Number: FISH8824R1

Title: Limitations of target detection in horizontal acoustic surveys of extremely shallow water bodies

Article Type: Research Paper

Keywords: Hydroacoustics, Horizontal beaming, Simulations, Water surface, Boundary induced errors

Corresponding Author: Professor Jan Kubecka, PhD

Corresponding Author's Institution: Academy of Science of the Czech Rep.

First Author: Ievgen Koliada, Mr.

Order of Authors: Ievgen Koliada, Mr.; Helge Balk, Dr.; Michal Tušer, Dr.; Ladislav Ptáček, Dr.; Jan Kubecka, PhD

Manuscript Region of Origin: CZECHIA

Abstract: The effect of target strength oscillations, generated by surface or bottom-induced sound multi-pathing, can cause serious errors in estimates of fish biomass in horizontal acoustic surveys of extremely shallow inland waters (depth $1.7-2 \mathrm{~m}$ ). In this study, the oscillations were shown to occur in both windy and calm weather conditions, and depended on the target's depth and range from a transducer. In calm weather the oscillations were more pronounced and targets that were located close to the water surface and further from the transducer were most affected. Errors in target strength reached up to an 8 dB difference from the theoretical value. Fish abundance and size structure estimates are likely to be affected even more than biomass estimates. To avoid boundary-induced errors in target strength, simulations of fish biomass surveys demonstrated that the data-processing range should be limited to $10 \mathrm{~m}$ from the transducer for surveys conducted in extremely shallow waters. 
Dear editor,

Please find a manuscript describing the behaviour of sound field during horizontal acoustic surveys of very shallow lakes. This area has been little studied and this kind of analyses appear crucial prior to shallow water fisheries surveys.

We believe it is a valuable contribution for Fisheries Research.

levgen Koliada, Helge Balk and Jan Kubečka 
First, we would like to say thanks to the reviewers for the useful comments to improve the paper. We have accepted all the comments as explained below.

\section{Reviewer \#1:}

Minor comments: We have fixed all of them.

"Line 21 use $8 \mathrm{~dB}$ instead of $8-\mathrm{dB}$

Line 65 should be $\mathrm{km}^{2}$ instead of $\mathrm{km} 2$

Line 84 should be "were" instead of "was"

Line 154 should be "shows" instead of "show"

Line 156 use "and/or" or just "or"

Line 202 delete "for"

Line 217 should be "shows" instead of "show"

Line 225 should be "was" instead of "where"

Line 227 should be "was" instead of "where"

Line 238 should be "denote" instead of "denotes"

Line 249 "paraments" should be "parameters "?

Line 256 add "conditions" at the end of the sentence"

Line 290 should be 3.3 instead of 3.2

Line 291 add "of" after "comparison"

Line 305 what you mean by "control values", please explain and indicate to which characteristics they refer (I guess abundance, fish size and biomass?)

Line 323 add at the end of the sentence "at MUR=10 m"

Line 338 after "both" add "calm and windy" (you must repeated this information because you start new paragraph)

Line 339 what you mean by "avoidance of spherical spreading", you wanted to say "disturbance of spherical spreading" or "changing pattern from spherical to cylindrical spreading"?

Line 349 add "of" after "influence"

Line 365 replace "form" with "from"

Line 444 should be "Kubečka" instead of „Kubečk"

Line 469 should be "Kubečka" instead of "Kube??ka"

Line 508 replace "equals" with "equal to"

Line 509 replace "on" by "at"”

"Lines 205-214 I am not sure if using catch data for fish simulated TS values was the best thing, as in this way estimates include errors associated with TS/L regression used."

We agree that introducing TS/L regression brings another recalculation of data but on the other hand, conversion to real fish parameters let us demonstrate the consequences of studied phenomena for "real world" of fishery relevant results.

"Lines 210, 219 Your TSsim (equation 4) is function of TL, but not R (equation 6). I do not see how you got the dependence on R"

Thank you, there was an error in equation, the equation 6 was corrected. 
"Lines 268-269 your statistical analyses showed that "the wind or state of surface and interaction were not significant ( $\mathrm{p}=0.183$ and $\mathrm{p}=0.113$ respectively)". This result is contrary to results presented in with Fig. 3 and your field surveys in Lake Neusiedl, where "Years when weather was very calm during the survey showed unreasonably high biomass values (2-4 times higher) compared with results from usual windy years"(lines 78-79). You should refer to this in the discussion"

We apologize for confusing statements. Biased results in calm weather were caused by the fact that calm weather with seemingly clean data and good SNR encouraged the use of longer surveyed ranges up to 18 meters (Herzig and Kubečka, 2001) creating thus the opportunity for the interference to influence the TS and biomass. This information was added to discussion (line 350-54).

"Lines 299-300 I may not agree with the statement "There is an important exception of this pattern at the depth of $15 \mathrm{~cm}$ on the ranges under $10 \mathrm{~m}$ (Fig 4), where the size of targets is usually underestimated". In Fig. 4 there are clear oscillations (with amplitude up to $5 \mathrm{~dB}$ ) of TS above and below TS theoretical in the range under $10 \mathrm{~m}$ at 3 depths: $0.15,0.25$ and 0.35 (and not just 0.15 ). From Table 3 it follows that size (weight) of fish and their biomass is highly overestimated at $0.15 \mathrm{~cm}$ TD (but this as I understand includes all ranges)."

The discrepancy the reviewer pinpoint is not real. In the ranges less than $10 \mathrm{~m}$ at target depth of $15 \mathrm{~cm}$ the TS is mostly less than theoretical value. From Table 3 it is clearly shown than when 10 $\mathrm{m}$ range is used we have underestimation of weight $(-82 \%)$. We improved the text to be more clear.

"Lines 375-376 correct the style of this sentence "It may be tempting to think that using a TS without beam pattern compensation as if we had a single beam system, but the advantages of such simplified approach should be tested in future studies." and explain in detail why using uncompensated TS should improve the estimates?"

It was rewritten as requested.

"Lines 385-387 I would not fully agree with the conclusion that in order to solve problems of TS variability it is enough to limit processing ranges from 4 to $10 \mathrm{~m}$. In my opinion your results clearly show that in extremely shallow environments acoustics is not a reliable tool for estimating fish biomass, and even less reliable for fish abundance. The agreement of your calculations with results obtained from trawling I see rather as just accidental, and not the proof for the effectiveness of proposed analysis procedure. "“

We made our conclusions weaker and more careful. In line with recommendations we also changed the title of paper.

\section{Tables}

"Table 1 
I would add to Table 1 information on 1997 survey in Lake Neusiedl, that was reanalyzed in this paper i.e. weather conditions, depth and tilt of the transducer and the corresponding depth range of TS analyses performed"

Information is added.

\section{"Table 2}

It happens that the highest $\mathrm{r}^{2}$ is for $\mathrm{TD}=0.15 \mathrm{~m}$ (it is probably why it was used in Fig.6), while in the middle part (which is suggested for analysis) it is the lowest. If this polynomial does not well describe the data, can we use it as a measure of error?"

The distribution of errors has high variability but even the polynoms with the lowest $r^{2}$ were statistically significant and had better fit than models with a single trend (linear and logarithmic). Higher $r^{2}$ means high error dependence on the range and good prediction of polynomial model but is not a good indicator of TS quality. Therefore, the data from the middle part of water column are less biased.

"Table 3

The adjustments make a huge difference and it is difficult to find any consistent pattern in it, so for me this table is not convincing to have any sense. I do not understand if there is any relation between "simulated control values" in Lake Neusiedl for biomass and average weight in Table 3 with those in Table 4? They are quite different."

There is no any relation between Table 3 and 4 . Table 4 just show how the values of biomass, abundance and average weight changed with shortening processing range in calm 1997 Neusiedl survey.

Table 4

I believe in the last row it should be just "Sv(dB)" and not " $\log \operatorname{Sv}(\mathrm{dB})$ ". I would add also to the table a separate row for fish abundance. I wonder if average weight $(\mathrm{g})$ was from the catches or estimated from acoustics? It is surprising that in spite of about one order of magnitude increase in biomass (between MUR = 10 and 20), the average fish weight in cruises 1.2 and 1.3 decreased, i.e. it was opposite than expected from the experimental setup. I wonder if reason for this could be that in experimental setup you used traditional signal detection (SED), while in analysis of survey data you used crossfilter. Don't you think that filter could introduce additional error? Have you used the same length window in both cases (0.4-1.7 times transmitter pulse)?

Yes it should be just "Sv(dB)" and not " $\log S V(d B)$ ". Average weight $(g)$ was estimated from acoustics. Thank you for catching this point. The data was re-analyzed because of wrong crossfilter parameters was used previously. This caused strange behavior of estimated average size. Separate row for fish abundance was added to Table 4. We also added Figure 11 showing the comparison of fish length-frequency when processing MUR 4-10 and 4-20 m.

\section{"Figures}

The captions should be more informative and clear indicate on which measurements they are based (which lake and was it experimental setup or the survey). Also try to be consequent in 
presenting the data, at the moment in Fig. 2 calm conditions are on left, windy on right, in Fig. 3. calm on right, windy on left, in Fig. 6. calm on left, windy on right picture (it is confusing)."

We improved the captions where applicable. The examples with calm conditions are now on the left, windy on the right side.

"Fig. 1.

As present, it is not clear which ray-tracing is for which profile. Since both, temperature and transducer deployment (depth and tilt angle) influence sound propagation I would expect either to have the Fig.1B for the different temperature profiles but the same transducer deployment, or (preferably) Fig.1B for $0.35 \mathrm{~m}$ depth and Fig.1C for $0.5 \mathrm{~m}$ depth of transducer and clear indication which of the pictures refer to which lake (T profile)"

Fig. 1 was modified as requested.

\section{Reviewer \#2:}

"My main criticism is that the paper needs a thorough language check. There are many typos and strange use of English. Test bane for example, seems to be a Norwegian word, at least I have not seen that term in English. I think survey is a better word that campaign, which to me is a military term. What is a "real" Lake Neusiedl campaign - are there imaginary ones? I also found words like re-examined data, perimenter, mot, paraments. What is a profound oscillation? Behaved similar (should be behaved similarly), English uses the decimal period, make sure you adjusted all numbers that uses decimal comma."

All these suggestions implemented. The English was kindly checked by Dr. Jon Hateley who is both native speaker and shallow water acoustics expert.

"Following text books, I think SV should be subscripted as SV Line 291 Did you define Svt as theoretical Sv somewhere. I did not find it. I assume that is what you mean, and that SVm is measured Sv. I might have missed it."

Different Sv values were defined at the material and methods section (line 245,246).

"Line 299 with increasing of R, better "with increasing range"”

Corrected, "R" was replaced with "range".

"Line 304: Sv corrupted by errors? Perhaps say Sv was not affected. Seems to me these effects are not really errors, they are the results of physics."

Replaced as requested. 
"Line 312 This sentence stating biases is too complicated. Break it up, as one has to read to the end to figure out that the numbers refer to MUR of 10 and 20 m."

This sentence was split into two.

"Line 317 Are you introducing errors? Or accounting for errors. Do not understand"

Yes we introduce the errors to simulation data. We explained this now more clearly in the text.

"Line 320 suggest: on the resulting estimates"

Corrected.

"Line 32210 times higher than the results of the same files ? What do you mean?"

We explained this more clearly.

"Line 326 suggest: Balk et al. (2017's results using a standard target."

Reference was changed.

“Line 330: noisier background ? noisier than what?"

We explained noisier picture more clearly and referred to a Figure 3.

"Line 339. Avoidance of spherical spreading? Do not understand."

Similarly to reviewer 1 changed to better term "disturbance"

"Line 341 suggest: but a cylindrical model can give more stable values for TS"

Corrected.

"Line 355 suggest: Using short ranges may lead to fish avoiding the survey vessel"

Corrected

“Line 367 "less may mean actually more". Poetic use of language but makes it less clear." Corrected. 
"Line 382 Conclusions. Do remind the reader that the processing ranges and MUR depends on the transducer and its beam pattern."

Done.

"Figure 6, decrease the size of the points."

Done. 


\section{Highlights:}

- Fish echoes in horizontal beaming in shallow waters are influenced by multipathing modified by the state of the surface.

- The targets close to the surface are most affected.

- The phenomenon can be observed for windy and calm weather condition.

- Most effects result in increasing average size, biomass and decreasing abundance.

- Maximum useable range and beam position should be adjusted to avoid sampling volumes closer than $20 \mathrm{~cm}$ to phase boundaries (surface, bottom). 


\title{
Limitations of target detection in horizontal acoustic surveys of extremely shallow
} water bodies.

Ievgen Koliada ${ }^{\mathrm{a}, \mathrm{b}}$, Helge Balk ${ }^{\mathrm{b}, \mathrm{c}}$, Michal Tušer ${ }^{\mathrm{b}}$, Ladislav Ptáček ${ }^{\mathrm{d}}$, Jan Kubečka ${ }^{\mathrm{b}, *}$

${ }^{\text {a }}$ Faculty of Fisheries and Protection of Waters, University of South Bohemia in České Budějovice, Zátiší 728/II, 38925 Vodňany, Czechia

${ }^{b}$ Biology Centre of the Czech Academy of Sciences, Institute of Hydrobiology, Na Sádkách 7, 37005 České Budějovice, Czechia

${ }^{c}$ Department of Physics, University of Oslo, PO. Box. 1048. Blindern, NO-0317 Oslo, Norway

${ }^{\mathrm{d}}$ Faculty of Sciences, University of South Bohemia in České Budějovice, Branišovská 31, 37005 České Budějovice, Czechia

\begin{abstract}
The effect of target strength oscillations, generated by surface or bottom-induced sound multi-pathing, can cause serious errors in estimates of fish biomass in horizontal acoustic surveys of extremely shallow inland waters (depth 1.7-2 m). In this study, the oscillations were shown to occur in both windy and calm weather conditions, and depended on the target's depth and range from a transducer. In calm weather the oscillations were more pronounced and targets that were located close to the water surface and further from the transducer were most affected. Errors in target strength reached up to an $8 \mathrm{~dB}$ difference from the theoretical value. Fish abundance and size structure estimates are likely to be affected even more than biomass estimates. To avoid boundary-induced errors in target strength, simulations of fish biomass surveys demonstrated that the dataprocessing range should be limited to $10 \mathrm{~m}$ from the transducer for surveys conducted in extremely shallow waters.

*Corresponding author kubecka@ @bu.cas.cz (J. Kubečka),

E-mail addresses: koliada@frov.jcu.cz (Koliada, I.), kubecka@hbu.cas.cz (J. Kubečka), helge.balk@fys.uio.no (H. Balk), michal.tuser@gmail.com (Tušer M.), lptacek@prf.jcu.cz (Ptáček L.).
\end{abstract}

\section{Keywords:}

Hydroacoustics, Horizontal beaming, Simulations, Water surface, Boundary induced errors 


\section{Introduction:}

Extremely shallow inland waters incorporate a considerable variety of habitats. The term 'extremely shallow' is a relative term, which could be defined as any environment (lakes, ponds, streams and rivers) where an average depth reaches up to $2 \mathrm{~m}$. In addition to the vertical spatial constraint, this type of environment is typically characterized by high turbidity, vegetation and often flat silty bottoms. These characteristics influence the methods appropriate for examining the fish communities.

For inland waters, many fish sampling methods have generally been developed for scientific purposes (CEN, 2006), but the most commonly used ones in Europe and other parts of the world are gillnetting and electrofishing (Blabolil et al., 2016; Bonar et al., 2009; CEN, 2005; Olin et al., 2009). These two methods are, unfortunately, selective (Kurkilahti et al., 2002; Prchalová et al., 2009; Ríha et al., 2012) with their efficiency depending on fish activity (Bethkea et al., 1999), gear saturation (Prchalová et al., 2010) and other factors. More importantly, they are destructive to the fish community in their environment (Blabolil et al., 2017; Winfield et al., 2009). In this respect, hydroacoustic surveying, being a remote observation technique, may partly circumvent these problems, especially in turbid or dark freshwater environments, where optical observation devices are not effective (Simmonds and MacLennan, 2005). In addition to being non-invasive, hydroacoustics offers the advantages of being able to detect and quantify a wide range of targets and sizes, from young of the year to large mature fish.

Horizontal echo-sounding is probably the most suitable acoustic approach for monitoring extremely shallow waters. The European Standard on the estimation of fish abundance with mobile hydroacoustic methods (CEN, 2014) specifies several recommendations for horizontallyaimed transducers in shallow waters. First, a transducer should emit a narrow sound beam with a short nearfield and well-damped side-lobes. Second, the transducer should be held on an adjustable platform allowing changes in both vertical (tilt) and horizontal (pan) planes. Third, the top of the transducer should be placed at least one vertical dimension of the transducer face below the water surface. Finally, the transducer should be mounted with a tilt giving Maximum Usable Range (MUR). This range is a function of transducer depth, tilt, beam geometry, water depth, and sound refraction (Kubečka, 1996).

Lake Neusiedl (Austria, Hungary) is among the shallowest large lakes in the world (Löffler, 1979). The open water zone (without reeds) covers $143 \mathrm{~km}^{2}$ and is no more than $1.8 \mathrm{~m}$ 
deep. The wind shear stress on the water surface causes resuspension of bottom sediments and is the principal reason for the high turbidity in the lake (Löffler, 1979). The high turbidity and the proximity to boundaries (surface and bottom) causes a high level of acoustic noise. A significant proportion of the fish community in the lake are small $(<10 \mathrm{~cm})($ Herzig and Kubečka, 2001; Jůza et al., 2013), and the combination of small fish and a high noise level gives a poor signal to noise ratio (SNR), making data processing a challenging task.

The lake has, however, been surveyed for 10 years in the period between 1997 and 2010. (Draštík and Kubečka, 2011; Herzig and Kubečka, 2001). The challenge of low SNR was addressed by replacing the traditional single echo detection and tracking method with the Cross Filter based Detection and tracking method (CFD) (Balk and Lindem, 2000).

Analyses of the acoustic dataset by Draštík and Kubečka (2011) and Herzig and Kubečka (2001) demonstrated a correlation between observed acoustic biomass and the prevailing weather conditions. In years when the weather was very calm during the survey, unexpectedly high biomass values (2-4 times higher) were observed compared with results from windy years. Later it was found that a smooth surface could influence echo sounder recordings even when the horizontally aligned main lobe was placed well below the surface. This was reported in Balk et al., (2017). Interactions between signals from the direct path and paths reflected by the specular surface caused range dependent interference. This interference affected TS measurements both directly and indirectly through the split-beam angle detector and off-axis gain compensation system. Three range-zones were observed when surface interactions occurred. A standard target moved away from the transducer would first be observed with a stable and correct TS (Zone 1). Then TS would start to increase and decrease in an oscillating manner with increasing amplitude and decreasing frequency (Zone 2). At long range (Zone 3), TS did not oscillate, but slowly decreased whilst approaching, but never reaching the correct value. The range for each zone depended on the transducer and target depth. Zone 2 could typically start around 8-12 meters away from the transducer.

The bottom may also affect the acoustic data in extremely shallow lakes. A smooth bottom will remain smooth even in windy situations, so it may be expected that interactions with the bottom could occur in all kinds of weathers. According to Urick (1983), the bottom is a complex reflecting and scattering boundary.

Due to these findings, we wanted to know more about the reliability of the surveys conducted on Lake Neusiedl. We conducted experiments with various transducer mountings, 
target depths and surface states. The TS oscillations were verified in windy and calm weather conditions and the dependence of oscillation characteristics on transducer deployment position and target depth were determined. We simulated surveys with and without the experimentally observed errors and re-examined data from one of the Lake Neusiedl surveys.

\section{Material and methods:}

\subsection{In-situ experiments}

The experimental work was carried out in Lake Neusiedl and in Bagr pond. At Lake Neusiedl the wind speed was approximately $8 \mathrm{~m} / \mathrm{s}$ during our tests (Windmaster 2 wind gauge). The smooth surface experiments were conducted in the sheltered Bagr pond located in the city of České Budějovice (Czech Republic). Here the wind speed was approximately $0 \mathrm{~m} / \mathrm{s}$ during our experiments. Both the lake and the pond are extremely shallow with a depth of 1.7 meters in the vicinity of the experiments. All experiments were done in areas with flat and smooth semi-solid clay bottoms. Water temperature profiles were stable at both study sites during the experiments (Fig. 1 A).

Our experimental setup worked like a cable car system (Fig. 2). Two step-ladders were fixed on the lake bottom at each side of the test area, and equipped with pulleys. A transporting rope ran in a loop through the pulleys with one end attached to the front and the other end to the rear of a windsurfing board. The windsurfer worked as a platform for the standard target. An arrangement with a wooden board and a stick on the surfboard ensured that the rope was lifted up from the water, and that the standard target hung from the stick well behind the surfboard. In this way, neither the rope nor the surfboard disturbed the acoustic recordings of the water body between the target and the transducer (Fig. 3).

The target was a SIMRAD standard calibration copper sphere (23 $\mathrm{mm}$ in diameter). According to SIMRAD's calibration datasheet, this sphere had a TS $=-40.85 \mathrm{~dB}$ in Lake Neusidl and $-40.8 \mathrm{~dB}$ in the Bagr pond according to the measured temperature and system operating frequency. The target was suspended from a monofilament fishing line designed for a low degree of stretching (thickness $0.35 \mathrm{~mm}$ ). The setup allowed us to position the target at different depths and to easily move it to any range from the transducer along the test rig. 
Acoustic data was collected with a SIMRAD EK60 echo-sounder equipped with an ES120-4x10 transducer operating at $120 \mathrm{kHz}$, and with a $4 \times 10^{\circ}$ opening angle. The EK60 was set up with a pulse duration of $0.128 \mathrm{~ms}$, and a power of $100 \mathrm{~W}$.

The transducer was mounted on a solid stand consisting of a metal frame placed on the lake bottom. A vertical rigid metal bar was attached to the frame through a lockable ball-joint and a bracket on the bar held the transducer. The ball-joint and bracket mounting enabled tilt and depth adjustments (Fig.2). The vertical bar extended above the surface so that tilt angle could easily be measured by holding a tilt gauge towards the bar. We used a Leica DISTOTM 5D laser range and tilt measurer for this. We verified that the transducer face was parallel with the rod. Transducer depth was measured with a mechanical ruler from the transducer center to the water surface. Two transducer depths were chosen for the experiments $(0.35$ and $0.50 \mathrm{~m})$ to match the depths applied during the 1997-2010 Lake Neusiedl surveys.

The elliptical-transducer was mounted with the long axis in the horizontal plane. This is common for horizontal shallow water monitoring setups and in accordance with the setup applied for the surveys conducted in Lake Neusiedl. The beam will then have the narrow opening angle in the vertical domain and the wide opening angle in the horizontal domain, providing an increased range and ensuring targets stayed longer in the beam relative to a mounting with the main axis in the vertical plane.

For re-examination of historic calm surface data from Lake Neusiedl, we chose the dataset from 1997. This dataset was recorded with a calibrated SIMRAD EY500 split-beam echo sounder equipped with the same ES120-4x10 transducer mounted in the front of the research vessel "Ota Oliva". The transducer was mounted in the same way as in the experimental setup with the transducer depth at $0.35 \mathrm{~m}$, tilted $1 \mathrm{deg}$. down.

\subsection{Data processing and simulation}

Sonar5-Pro (Lindem Data Acquisition, Oslo, Norway) was applied for prediction of beam behavior and for post-processing of the acoustic data. Microsoft ${ }^{\circledR}$ Excel and the R package was applied for the statistics while MATLAB 7.1 software was applied for the simulations.

Sonar5-Pro's ray-tracing module was applied to test the theoretical behavior of the beam in the waterbody and to obtain a theoretical maximum range. The module simulates the beam placement in the water column based on the transducer mounting, opening angle and measured temperature profiles. Fig 1 B shows simulation results for our setup. In the simulations we see 
indications of refraction and that a range of about $20 \mathrm{~m}$ can be expected before the main beamlobe hits either the surface or bottom.

Traditional single echo detection (SED) and tracking was applied to collect information from the standard target moved along the test rig. Information on range, TS and angular position were exported to Microsoft $\circledast$ Excel for further evaluation.

For re-examination of historic calm surface data from Lake Neusiedl, we applied Sonar5Pro's Cross Filter Detector (CFD) (Balk and Lindem, 2012). The CFD method uses filters to separate fish from noise. One filter is tuned for improving fish signals and reducing noise whilst the other filter is tuned to focus on noise and suppress fish. An offset is added to the latter and the output from the two filters are compared to detect the fish traces. The results were evaluated using criteria such as track length, perimenter and elongation. Tracks failing to meet the thresholds for a fish were removed. For the 1997 data set, the CFD was set up with the following criteria; foreground filter height $=1$, width $=5$; background filter height $=55$, width $=1$; offset 6 $\mathrm{dB}$. For the evaluator stage, tracks shorter than 4 echoes and longer than 200 echoes were rejected. The acceptable number of samples in the track perimeter was set from 10 to 158 and the mean echo length window was set from 0.4 to 1.7 times the transmitter pulse. The output from the CDF was scrutinized, and echoes believed to occur from submerged vegetation were manually erased. The characteristic shape and sizes of submerged vegetation have been described by Hohausová et al. (2008).

Fish abundance was determined by sv/ts-scaling. For estimating fish length from acoustic size, a relationship from Frouzova et al. (2005) was used. Deconvolution of the TS data was performed according to Kubecka et al. (1994). Data for length-weight relationship was taken from Herzig et al. (1994) for average lake fish. Data were processed for two ranges; 4-10 and 420 meters. The lower limit was set to reduce bias due to transducer near-field effects, boat avoidance and small sampling volume.

\subsubsection{Calculation of error in TS}

Deviation between the measured and the theoretical TS along the test rig shows the influence of the environment. The theoretical TS value is the value predicted by the datasheet for the standard target for the measured temperature, while the measured TS is taken from each SED recorded from the target. From this we can calculate the error caused by the environment for each observation: 


$$
T S_{\text {err }, i}=T S_{m, i}-T S_{t}=10 \log \left(\frac{\sigma_{m, i}}{\sigma_{t}}\right)
$$

191

192

193

where subscript $m$ and $t$ indicate measured and theoretical values respectively. Index $i$ indicates the SED observation number and $\sigma$ is the backscattering cross-section.

To compare errors resulting from the different transducer mounting and target depths, Mean Square Error (MSE) was used:

$$
M S E_{j}=\frac{1}{N} \sum_{i=1}^{N} T S_{e r r, i}^{2},
$$

To see the overall error for each experiment, the average of the sigma ratios was found for each experiment.

$$
\bar{\sigma}_{e r r, j}=\frac{1}{N} \sum_{i=1}^{N}\left(\frac{\sigma_{m, i}}{\sigma_{t}}\right)=\frac{1}{N \sigma_{t}} \sum_{i=1}^{N}\left(\sigma_{m, i}\right)
$$

Index $\mathrm{j}$ is the experiment number and $\mathrm{N}$ the number of observations for the $\mathrm{j}^{\text {th }}$ experiment. Multivariate ANOVA was applied to show the relationship between the MSE, transducer mounting, target depth and surface state.

\subsubsection{Simulating fish biomass to model the impact of the oscillations}

To investigate the influence of the environment on final biomass estimates, we simulated acoustic data for a Lake Neusiedl survey with and without the errors due to boundary effects. The simulation dataset comprised 25000 fish obtained from 120000 pings in accordance with average values from the real surveys (Draštík and Kubečka, 2011).

Simulated fish TS values were calculated from trawl catch data reported by Jůza et al. (2013) as Total Lengths (TL mm) using a normal length distribution with mean and standard deviation of $98 \mathrm{~mm}$ and $151 \mathrm{~mm}$ respectively. Lengths were converted to TS according to the pooled species regression of Frouzova et al. (2005) for European lake species.

$$
\mathrm{TS}_{\mathrm{sim}}=24.73 \cdot \log 10(\mathrm{TL})-103.61
$$

$\mathrm{TS}_{\text {sim }}$ was used as the basis for the simulation of the "true" biomass without influence from either surface or bottom. To include the error caused by the surface or bottom, a third order polynomial was obtained from the experimental data and applied to adjust the simulated target strengths (Fig. 6): 
218

219

220

221

222

223

224

225

226

227

228

229

230

231

232

where $a, b, c$, and $d$ are coefficients of regression, $R$ is the range from the transducer, and $j$ the index of the experiment number. Table 2 shows regression factors for the conducted experiments. Adjustment of the "true" target strength for a simulated fish was done as follows:

$$
T S_{\text {corr }, j}(T L, R)=T S_{\text {sim }}(T L)+10 \log \left(\sigma_{e r r, j}(R)\right)
$$

For the simulation of the fish abundance and biomass we also need to find the volume backscattering strength $\left(\mathrm{S}_{\mathrm{V}}\right)$. For a target on axis, $\mathrm{S}_{\mathrm{V}}$ relates to TS through the pulse volume $(\mathrm{Vp})$. For a target off axis, the beam pattern is also involved:

$$
S_{v}=T S-V p(R)-B(\varphi, \theta)(7)
$$

where $\mathrm{R}$ is the range, and $\varphi$ and $\theta$ are the angle variables in the transducer's along- and athwartship domains. In our simulations, $\theta$ was held constant at zero while Table 1 shows the various values of $\varphi$ applied in the simulations.

The pulse volume was found from the sound speed $\mathrm{c}$, the pulse duration $\tau$, the range $\mathrm{R}$, and the equivalent opening angle $\psi$ in the following way:

$$
V_{p}(R)=10 \log \left(\frac{c \tau}{2} \psi R^{2}\right)
$$

According to Simrad, we can estimate the applied part of the beam pattern with a second order Bessel function as follows:

$$
B(\varphi, \theta)=3\left[\left(\frac{\varphi}{u_{1}}\right)^{2}+\left(\frac{\theta}{u_{2}}\right)^{2}-0.18\left(\frac{\varphi}{u_{1}}\right)^{2}\left(\frac{\theta}{u_{2}}\right)^{2}\right]
$$

here $u_{1}$ and $\mathrm{u}_{2}$ are the transducers half power opening angles in the along- and athwartship domains respectively.

The total number of simulated samples (M) was defined through the range resolution $(\Delta R)$ and number of pings $(\mathrm{P})$ :

$$
M=P \cdot \frac{\left(R_{2}-R_{1}\right)}{\Delta R}
$$

where $R_{1}$ and $R_{2}$ denote the beginning and end of the analyzed range. We simulated for $R_{1}=4$ $\mathrm{m}$ and $R_{2}$ up to $20 \mathrm{~m}$ with steps of $1 \mathrm{~m}$. Simulated fish abundance (fish/ha) was then found using the sv/ts-scaling method: 


$$
\# f i s h / h a=\frac{s v}{t s} \cdot\left(R_{2}-R_{1}\right), s v_{\operatorname{sim}}=\frac{1}{M} \sum_{i=1}^{N} 10^{\frac{s v_{s i m}, i}{10}}, t s_{s i m}=\frac{1}{N} \sum_{i=1}^{N} 10^{\frac{T S_{s i m}, i}{10}}
$$

244

245

246

247

248

249

250 where $\mathrm{N}$ is number of fish.

251

252

253

254

255

256 (1994):
Each individual $\mathrm{TS}_{\text {sim }}$ and $\mathrm{TS}_{\text {corr }}$ was converted to fish length through reversing Eq. 4 and then to weight using the length-weight relationship for Lake Neusiedl reported by Herzig et al.

$$
w_{\text {simi }}=3.437 \cdot 10^{-6} \cdot \mathrm{TL}_{\text {sim, }, i}^{3.145}
$$

Finally, biomass (kg/ha) for a simulated survey $\mathrm{j}$ becomes:

$$
\mathrm{kg} / \mathrm{ha}_{j}=\frac{1}{N} \sum_{i=1}^{N} w_{\text {sim, } \mathrm{i}} / 1000 \times \# \text { fish } / \mathrm{ha}
$$

Eq. (7) and Eq. (9) were used for calculating $S_{\mathrm{V}}$ (theoretical $\mathrm{S}_{\mathrm{V}}$ ) and computing $\mathrm{S}_{\mathrm{V}} \mathrm{m}$ (measured $S_{V}$ ) from uncompensated TS values for each setup (Table 1). $S_{V m}$ is a function of the range and not the average $S_{\mathrm{V}}$ for the whole analyzed layer. When calculating $S_{\mathrm{V}} t$, it was assumed targets remained in the center of the horizontal axis. 


\section{Results}

\subsection{Influence of weather conditions on TS measurements}

First, we checked the appearance of TS oscillations in calm (Bagr pond) and windy (Lake Neusiedl) conditions. Deviation from the theoretical $\mathrm{TS}_{\mathrm{t}}$ for the standard target was observed under both smooth and rough surface conditions. In the calm Bagr pond, the target strength behaved as reported in Balk et al. (2017), demonstrating strong TS oscillations throughout zone 2, increasing in amplitude and decreasing in frequency with increasing range. For the rough surface in Lake Nesusiedl, the oscillation was also observed, although less marked. Fig. 3 and 4 show TS measurements for the calm and rough surfaces. Due to the noise caused by surface reverberation, the MUR decreased to $10 \mathrm{~m}$ on Lake Neusiedl for the $0.35 \mathrm{~m}$ transducer depth. The target was barely distinguishable after $10 \mathrm{~m}$ as the SNR was too low.

Secondly, differences between the measured TS values in calm (Bagr pond) and windy (Lake Neusiedl) weather conditions were tested for the $0.35 \mathrm{~m}$ transducer depth. A two-way ANOVA was used to test for the influence of wind, target depth and interaction between these factors on the resulting TS values. Comparison of these factors indicated that the wind (state of surface) and interaction were not significant $(\mathrm{p}=0.183$ and $\mathrm{p}=0.113$ respectively), but target depth contributed significantly $(\mathrm{p}=0.047)$. Comparisons of MSE for the $0.35 \mathrm{~m}$ transducer depth showed the only significant difference was for the $0.15 \mathrm{~m}$ target depth (Fig. 5). This was caused by the large oscillation peak (Fig. 6) in windy (Lake Neusiedl) conditions beyond $10 \mathrm{~m}$ range. The errors in TS at the $0.5 \mathrm{~m}$ transducer depth for different transducer tilt angles behaved similarly under both weather conditions (Fig. 7).

\subsection{Dependence of TS oscillations on transducer deployment position and target depth}

Standard target measurements at different depths from Bagr pond (calm weather) were used in the evaluation of errors and their dependence on transducer depth and inclination. Fig. 8 indicates that TS measurements from the different transducer deployment positions behaved similarly. In all cases the error was dramatically larger for the shallowest targets (MSE > $20 \mathrm{~dB}$ ), dropping to 5-20 dB for targets suspended at $0.3-1.4 \mathrm{~m}$. Increasing transducer depth and tilt angle only resulted in a decrease in MUR and a slight change in the surveyed part of the water column from surface towards the bottom (comp. Fig. 1B and C). 
Fig. 4 demonstrates the trend of increasing amplitude and decreasing TS oscillation

287 frequency with increasing of range. The oscillation region and the number of peaks are dependent on target depth. Table 2 shows the regression coefficients for the $\sigma_{e r r, j}$ function of measured TS by range (R) at both study sites for different target depths. The TS of targets 10 to $20 \mathrm{~m}$ from the transducer were predominantly overestimated for all target depths (Fig. 4). Shallow targets at depths less than 0.5 meters were generally more influenced by oscillations, where MSE reached $64 \mathrm{~dB}$ (Fig. 5).

\subsection{Influence of TS oscillations on fish biomass estimation}

From comparisons of $S_{\mathrm{V}} t$ and $S_{\mathrm{V}} \mathrm{m}$ (Fig.9) it was clearly seen that $\mathrm{S}_{\mathrm{V}}$ measurements were not affected but generally followed the expected pattern according to Eq. (7). There were, however, small deviations from $\mathrm{S}_{\mathrm{V}} \mathrm{t}$ which were a product of experimental limitations, i.e. the ability to hold a target in center of the beam and through random variations in reflections.

The TS oscillations lead to overestimation of the biomass and average fish weight under different weather conditions. Simulation showed that targets positioned close to the boundaries (surface and bottom, target depth 0.15 and $1.05 \mathrm{~m}$ ) and greater than $10 \mathrm{~m}$ range were most affected by TS oscillations (Table 3). This means the same fish at these depths looks bigger with increasing range. There is an important exception to this pattern at the depth of $15 \mathrm{~cm}$, where the size of targets is underestimated at most ranges under $10 \mathrm{~m}$ (Fig 4). Overestimation of size is highest at long ranges under calm (Bagr pond) weather conditions. The simulation for different MUR values shows that beyond $10 \mathrm{~m}$ range, the average values of abundance and weight change substantially (Fig. 10). This occurs because in all simulated target depth layers TS is overestimated after $10 \mathrm{~m}$ range yet $\mathrm{S}_{\mathrm{V}}$ is unaffected by errors.

Table 3 gives the simulation control values of biomass, abundance and fish weight derived from a fixed number of fish (25000 individuals per calculated total volume defined by MUR) and the size structure derived by trawling (Juza et al., 2013). For MUR=10 m in Bagr pond; biomass $=39.56 \mathrm{~kg} / \mathrm{ha}$, average abundance $=3416 \#$ fish $/$ ha and average weight $=12 \mathrm{~g}$. For MUR $=20 \mathrm{~m}$, simulated control biomass $=19.42 \mathrm{~kg} \mathrm{ha}^{-1}$, abundance $=1704 \mathrm{\# fish} / \mathrm{ha}$ and average weight $=11 \mathrm{~g}$. When simulating the signal bias in individual target depth layers, the average simulation results for the whole water column (Table 3) showed that biomass was $27 \%$ 
error adjustment for MUR=10 m. For MUR=20 m, biomass was $39 \%$ overestimated, abundance $58 \%$ underestimated, and the average weight $345 \%$ overestimated after error adjustment.

The simulation control values at short ranges (MUR=10 m) under windy (Lake Neusiedl) weather conditions resulted in biomass $=38.57 \mathrm{~kg} / \mathrm{ha}$, abundance $=3378 \mathrm{\# fish} / \mathrm{ha}$ and average weight $=11 \mathrm{~g}$. After introducing errors to the simulation, average biomass $=12 \%$ overestimated, average abundance $=33 \%$ underestimated, and average weight $=72 \%$ overestimated $($ Table 3 ).

In order to see the effect of shortened processing range (MUR $=10 \mathrm{~m}$ ) on un-simulated estimates of biomass, we reprocessed in situ data from the 1997 survey. Data reprocessing demonstrated that biomass estimation results using MUR $=20 \mathrm{~m}$ could be considerably higher than the results of the same files processed at MUR=10 $\mathrm{m}$ (Table 4). The increase in estimated biomass was mainly due to the increase in target size, thereby increasing the average weight (Table 4), and the higher frequency of larger targets (Fig. 11) at MUR=20 m.

\section{Discussion}

Our observations confirmed the unwanted oscillations in standard target TS reported by Balk et al. (2017), particularly under calm conditions. Balk et al. (2017) predicted that oscillations should be less apparent when the water surface is disturbed and this was confirmed in the windy conditions at Lake Neusiedl where cyclical changes in standard target TS were recorded, albeit with a less clear pattern (Fig. 3). These results were unexpected and may indicate that interference from the bottom may also have occurred. The oscillations are probably related not only to the state of the surface and bottom but also to lake depth. This study demonstrated clearly that the state of the surface or weather conditions do not remove errors in TS measurements completely, even when the transducer is tilted away from the surface and deployed deeper. However, the errors have different characteristics; regular oscillations in calm weather and a "cloud" of variation in windy conditions. The experimental data from Lake Neusiedl (windy) did not have a sufficient MUR to clearly show the data beyond $10 \mathrm{~m}$ range.

For both calm and windy situations, the trend lines show a slow increase in $\mathrm{TS}_{\mathrm{m}}$ with increasing range. This may also indicate a disturbance in spherical spreading in addition to the observed oscillation interference phenomena. In horizontal fisheries hydroacoustic biomass estimation methods, a spherical spreading model has been assumed, but a cylindrical model can give more stable values for TS (Balk, 2001). In order to control errors due to this phenomenon and to improve fish-sizing based on TS, two methods were developed in horizontal riverine 
applications (the MET-MIT-statistic and the 95th TS-percentile) (Rakowitz et al., 2008). However, in our case we cannot distinguish oscillations and cylindrical spreading and apportion errors accordingly. The possibility of cylindrical spreading underlines the need to avoid phase boundaries during the surveys (see below).

Our experiments showed that the above-mentioned interferences can affect biomass estimation more seriously than simple scattering of noise from a disturbed surface. The purpose of the simulation exercises was not to fully recreate reality, but to assist in verifying the influence of TS oscillations on biomass estimations and link it to the previous surveys of Lake Neusiedl. Calm weather with seemingly clean data and a good SNR encouraged the use of longer surveyed ranges of up to 20 meters (Herzig and Kubečka, 2001), thereby increasing the chances of the interference influencing TS and biomass. Reducing the maximum data processing range to a rather short range $(M U R=10 \mathrm{~m})$ ensured that no strong interference near the surface and bottom occurred. In this way, most of the affected fish detections were not included in the stock analysis. This range reduction led to a decrease in estimated fish biomass by more than one level of magnitude and helped to rectify the unrealistically high biomasses reported for the 1997 survey by Herzig and Kubečka (2001). Restricting analyses to a short range may lead to sampling fish that are actively avoiding the survey vessel (Draštík and Kubečka, 2005; Wheeland and Rose, 2015). However, most avoidance behavior was demonstrated by small fish that could not cause serious errors in fish biomass estimations. Also, it seems that boat avoidance is much lower at night when all these surveys are executed (Rakowitz et al., 2012). Fish biomass values estimated with MUR limited to $10 \mathrm{~m}$ brought the 1997 Lake Neusiedl results to a similar level estimated independently by trawling (Jůza et al., 2013, $12 \mathrm{~kg} . \mathrm{ha}^{-1}$ ).

As no significant difference was observed between different transducer deployment positions, the main challenge of a fieldworker is to avoid the areas close to the surface and the bottom, where the errors in target sizing are the largest (Fig. 4, 5, 8, Table 3). The most reliable data clearly came from the midwater layers, separated by at least $20 \mathrm{~cm}$ from the nearest phase boundary (Fig.12). Our results and simulations showed that although it is tempting to maximize sampling volume under calm conditions, targeting the maximum range may seriously affect the results. Use of a reduced MUR and avoiding phase boundaries gives a more reliable picture of the fish community in the lake. Applying MUR $=10 \mathrm{~m}$ unavoidably leads to reductions in sampling volume, so in order to achieve the same sampling volume, the number or length of cruise transects should be increased. 
It is encouraging to see that volume backscattering strength $\left(\mathrm{S}_{\mathrm{V}}\right)$ does not seem to be changing unpredictably with range, in the middle of the beam at least. This is in agreement with the findings of Draštík and Kubečka (2005) who found $S_{V}$ independent of range in horizontal hydroacoustic records in a similar environment (shallow Lake Balaton). All this confirms $\mathrm{S}_{\mathrm{V}}$ as a robust proxy of fish biomass. It may be tempting to think that using TS without beam pattern compensation, as if we had a single beam system, can reduce TS errors. In deep water surveys, uncompensated TS is more incorrect than compensated TS acquired by a split-beam echosounder and compensated for the off-axis loss (Balk et al., 2017), but potentially this may not be the case for very shallow surveys. The advantages of such a simplified approach should be tested in future studies. Transducers with better side lobe suppression than the ES120 4x10 transducer used can reduce the effects of fluctuations in similar locations and should also be tested. For example, the E120-7C transducer (circular beam shape with $7^{\circ}$ opening angle), which was used in studies of Lake Balaton (György et al., 2012; Tátrai et al., 2008).

\section{Conclusions}

The experiments and tests showed that unbiased acoustic stock assessment in shallow lakes is extremely challenging and can be subject to invisible errors. Fish abundance and size structure can be influenced more than the biomass. The main factors, which influence on TS, were range and target depth. Targets furthest from boundaries are least biased. Researchers using horizontal beaming applications in extremely shallow water bodies should use narrow beams with low side lobes and aim transducers in the direction of midwater layers. For future surveying in such environments, we recommend limiting processing ranges from 4 to $10 \mathrm{~m}$ which seem to be less affected by boundary interference and have the highest SNR. Regardless, the acoustic results should be viewed with caution and independent estimates should be used wherever possible.

\section{Acknowledgements}

This work was supported by the Institute of Hydrobiology and Biological Station Neusidler See in Illmitz. The authors thank Dr. Asanka Jayasinghe for his help during the field works at Bagr pond, Professor Alois Herzig for his support during the field works at the Lake Neusiedl and Dr. Tomáš Mrkvička for advise on statistical analyses. Great thanks also go to Dr. 
408 Olga Koba for stimulating discussion and comments. The English was kindly checked by Dr. Jon 409 Hateley.

410 
412

Balk, H., 2001. Development of hydroacoustic methods for fish detection in shallow water. Science (80-. ). Uneversity of Oslo, Norway.

Balk, H., Lindem, T., 2012. Sonar4 and Sonar5-Pro Post processing systems operator manual version 6.0.1.

Balk, H., Lindem, T., 2000. Improved fish detection in data from split-beam sonar. Aquat. Living Resour. 13, 297-303. https://doi.org/10.1016/S0990-7440(00)01079-2

Balk, H., Søvegjarto, B.S., Tušer, M., Frouzová, J., Muška, M., Draštík, V., Baran, R., Kubečka, J., 2017. Surface-induced errors in target strength and position estimates during horizontal acoustic surveys. Fish. Res. 188, 149-156. https://doi.org/10.1016/j.fishres.2016.12.017

Bethkea, E., Arrheniusb, F., Cardinaleb, M., Håkanssonb, N., 1999. Comparison of the selectivity of three pelagic sampling trawls in a hydroacoustic survey. Fish. Res. 44, 15-23. https://doi.org/doi.org/10.1016/S0165-7836(99)00054-5

Blabolil, P., Boukal, D.S., Ricard, D., Kubečka, J., Ř́ha, M., Vašek, M., Prchalová, M., Čech, M., Frouzová, J., Jůza, T., Muška, M., Tušer, M., Draštík, V., Šmejkal, M., Vejř́́k, L., Peterka, J., 2017. Optimal gillnet sampling design for the estimation of fish community indicators in heterogeneous freshwater ecosystems. Ecol. Indic. 77, 368-376. https://doi.org/10.1016/j.ecolind.2017.02.036

Blabolil, P., Logez, M., Ricard, D., Prchalová, M., Ř́ha, M., Sagouis, A., Peterka, J., Kubečka, J., Argillier, C., 2016. An assessment of the ecological potential of Central and Western European reservoirs based on fish communities. Fish. Res. 173, 80-87. https://doi.org/10.1016/j.fishres.2015.05.022

Bonar, S.A., Hubert, W.A., Willis, D.W., 2009. Standard methods for sampling North American freshwater fishes. American Fisheries Society, Bethesda, Meryland.

CEN, 2014. EN 15910, Water quality - guidance on estimation of fish abundance with mobile hydroacoustic methods. Eur. Com. Stand.

CEN, 2006. EN 14962, Water quality - guidance on the scope and selection of fish sampling methods. Eur. Com. Stand.

CEN, 2005. EN 14757, Water quality - sampling of fish with multimesh gillnets. Eur. Com. Stand.

Draštík, V., Kubečka, J., 2011. Report on acoustic fish stock assessment of Neusiedler See, August 2010. České Budějovice.

Draštík, V., Kubečka, J., 2005. Fish avoidance of acoustic survey boat in shallow waters. Fish. Res. 72, 219-228. https://doi.org/10.1016/j.fishres.2004.10.017

Frouzova, J., Kubecka, J., Balk, H., Frouz, J., 2005. Target strength of some European fish species and its dependence on fish body parameters. Fish. Res. 75, 86-96. 
448

449

450

451

452

453

454

455

456

457

458

459

460

461

462

463

464

465

466

467

468

469

470

471

472

473

474

475

476

477

478

479

480

481

482

483

484

György, Á.I., Tátrai, I., Specziár, A., 2012. Relationship between horizontal hydroacoustic stock estimates and gillnet catches of surface-oriented fish in shallow Lake Balaton (Hungary). Knowl. Manag. Aquat. Ecosyst. 06. https://doi.org/10.1051/kmae/2012012

Herzig, A., Kubečka, J., 2001. Fish biomass distribution in Neusiedler See (Austria): a hydroacoustic assessment of fish stock. Verhandlungen der Int. Vereinigung für Limnol. 27, 3660-3665. https://doi.org/doi.org/10.1080/03680770.1998.11902511

Herzig, A., Mikschi, E., Auer, B., Hain, A., Wais, A., Wolfram, G., 1994. Fischbiologische Untersuchung des Neusiedler Sees. Biol. Forschungsinstitut für Burgenl. 81, 125 pp.

Hohausová, E., Kubečka, J., Frouzová, J., Husák, Š., Balk, H., Husák, S., Balk, H., 2008. Experimental Biomass Assessment of Three Species of Freshwater Aquatic Plants by Horizontal Acoustics. J. Aquat. Plant Manag. 46, 82-88.

Jůza, T., Rakowitz, G., Draštík, V., Blabolil, P., Herzig, A., Kratochvíl, M., Muška, M., Ř́ha, M., Sajdlová, Z., Kubečka, J., 2013. Avoidance reactions of fish in the trawl mouth opening in a shallow and turbid lake at night. Fish. Res. 147, 154-160. https://doi.org/10.1016/j.fishres.2013.05.008

Kubečka, J., 1996. Use of horizontal dual-beam sonar for fish surveys in shallow waters, in: Cowx I. G. (Ed.): Stock Assessment in Inland Fisheries Fishing News Books. Blackwell, Oxford, UK, pp. 165-178.

Kubečka, J., Duncan, A., Duncan, W.M., Sinclair, D., Butterworth, A.J., 1994. Brown trout populations of three Scottish lochs estimated by horizontal sonar and multimesh gill nets. Fish. Res. 20, 29-48. https://doi.org/10.1016/0165-7836(94)90004-3

Kurkilahti, M., Appelberg, M., Hesthagen, T., Rask, M., 2002. Effect of fish shape on gillnet selectivity: a study with Fulton's condition factor. Fish. Res. 54, 153-170. https://doi.org/doi.org/10.1016/S0165-7836(00)00301-5

Löffler, H., 1979. Neusiedlersee: The Limnology of a Shallow Lake in Central Europe. The Hague - Boston - London.

Olin, M., Malinen, T., Ruuhijärvi, J., 2009. Gillnet catch in estimating the density and structure of fish community - Comparison of gillnet and trawl samples in a eutrophic lake. Fish. Res. 96, 88-94.

Prchalová, M., Kubečka, J., Ř́ha, M., Mrkvička, T., Vašek, M., Jůza, T., Kratochvíl, M., Peterka, J., Draštík, V., Křižek, J., 2009. Size selectivity of standardized multimesh gillnets in sampling coarse European species. Fish. Res. 96, 51-57. https://doi.org/doi.org/10.1016/j.fishres.2008.09.017

Prchalová, M., Mrkvička, T., Kubečka, J., Peterka, J., Čech, M., Muška, M., Kratochvíl, M., Vašek, M., 2010. Fish activity as determined by gillnet catch: A comparison of two reservoirs of different turbidity. Fish. Res. 102, 291-296. https://doi.org/10.1016/j.fishres.2009.12.011 
Rakowitz, G., Herold, W., Fesl, C., Keckeis, H., Kubečka, J., Balk, H., 2008. Two methods to improve the accuracy of target-strength estimates for horizontal beaming. Fish. Res. 93, 324-331. https://doi.org/10.1016/j.fishres.2008.06.005

Rakowitz, G., Tušer, M., Ř́ha, M., Jůza, T., Balk, H., Kubečka, J., 2012. Use of high-frequency imaging sonar (DIDSON) to observe fish behaviour towards a surface trawl. Fish. Res. 123-124, 37-48. https://doi.org/10.1016/J.FISHRES.2011.11.018

Ř́ha, M., Jůza, T., Prchalová, M., Mrkvička, T., Čech, M., Draštík, V., Muška, M., Kratochvíl, M., Peterka, J., Tušer, M., Vašek, M., Kubečka, J., 2012. The size selectivity of the main body of a sampling pelagic pair trawl in freshwater reservoirs during the night. Fish. Res. 127-128, 56-60. https://doi.org/doi.org/10.1016/j.fishres.2012.04.012

Simmonds, J., MacLennan, D., 2005. Fisheries acoustics: theory and practice. Blackwell, Oxford, UK. https://doi.org/10.1007/BF00043522

Tátrai, I., Specziár, A., György, A.I., Bíró, P., 2008. Comparison of fish size distribution and fish abundance estimates obtained with hydroacoustics and gill netting in the open water of a large shallow lake. Ann. Limnol. 44, 231-240. https://doi.org/10.1051/limn:2008007

Urick, R.J., 1983. Principle of Underwater Sound. McGraw-Hill, New York.

Wheeland, L.J., Rose, G.A., 2015. Quantifying fish avoidance of small acoustic survey vessels in boreal lakes and reservoirs. Ecol. Freshw. Fish 24. https://doi.org/10.1111/eff.12126

Winfield, I.J., Fletcher, J.M., James, J. Ben, Bean, C.W., 2009. Assessment of fish populations in still waters using hydroacoustics and survey gill netting: Experiences with Arctic charr (Salvelinus alpinus) in the UK. Fish. Res. 96, 30-38. https://doi.org/10.1016/j.fishres.2008.09.013 
Fig. 1. A) Temperature depth profiles during the surveys. Ray-tracing scheme of the $3 \mathrm{~dB}$ beam within water column (Sonar5-Pro) for transducer depth B) $0.35 \mathrm{~m}$ and C) $0.5 \mathrm{~m}$ with $1^{\circ}$ downward tilt: Left: Lake Neusiedl (windy); right: Bagr pond (calm). Black solid line is the bottom. Green is transducer axis.

Fig. 2. Experimental setup: Upper: Illustration of the deployment of a transducer and standard target at both study sites. Dashed arrows indicate directions of movement of the transducer and the calibration sphere. Lower left: Photo of a transducer stand being transported to the experiment site at Lake Neusiedl. Lower right: Photo of the experimental setup at Bagr pond with operator.

Fig. 3. Measured oscillations of TS in different weather conditions: Left: Lake Neusiedl (windy); right: Bagr pond (calm). The state of the water surfaces can be seen in the photos. The transducer was mounted $0.35 \mathrm{~m}$ below the surface and tilted $1^{\circ}$ down. The target was moved away from the transducer at a constant depth of $0.35 \mathrm{~m}$. Red dashed line indicates the theoretical value of the standard target TS over the whole range.

Fig. 4. Measured oscillations of compensated TS with range at target depth (TD) equal to 0.15, 0.25, 0.35, 0.5, 0.6 and $0.85 \mathrm{~m}$. The transducer was placed at Bagr pond at a depth of $0.35 \mathrm{~m}$ and tilted $1^{\circ}$ down. Red dashed line indicates the theoretical value of the standard target TS over the whole range.

Fig. 5. Comparisons of MSE for different target depths from Lake Neusiedl (windy) and Bagr pond (calm) with the transducer placed at a depth of $0.35 \mathrm{~m}$ and tilted $1^{\circ}$ down. The error bars show the low values of standard errors.

Fig. 6. Example of the dependences between $\sigma_{e r r, j}$ and range with interpolated $3^{\text {rd }}$ order polynomial curve (black solid line) from Lake Neusiedl (left chart) and Bagr pond (right chart). The transducer was placed at a depth of $0.35 \mathrm{~m}$ and tilted $1^{\circ}$ down. The target was moved away from the transducer at a constant depth of $0.15 \mathrm{~m}$. 
539 Fig. 7. Comparisons of MSE for different transducer tilt angles from Lake Neusiedl (windy) and 540 Bagr pond (calm) with the transducer placed at a depth of $0.5 \mathrm{~m}$. The error bars show the low 541 values of standard errors.

542

543 Fig 8. Comparisons of MSE for different target depths with A) different transducer depths and a 544 fixed transducer tilt of $1^{\circ}$ and B) different transducer tilt angles and a fixed transducer depth of $5450.5 \mathrm{~m}$. The experiment was conducted at Bagr pond. The error bars show the low values of 546 standard errors.

547

548

Fig. 9. Example of comparisons of $S_{\mathrm{V}} \mathrm{m}$ and $\mathrm{S}_{\mathrm{V}} \mathrm{t}$ for a target at $0.65 \mathrm{~m}$ depth at Bagr pond. The 549 transducer was placed at a depth of $0.35 \mathrm{~m}$ and tilted one degree down. $\mathrm{S}_{\mathrm{V}} \mathrm{t}$ was calculated using 550 Eq. (7).

551

552 Fig. 10. Percentage change of simulated average biomass, abundance and average weight for 553 different MUR. Adjustment for error was performed using $\sigma_{e r r, j}$ for Bagr pond (calm).

554

555 Fig. 11. Example of relative length-frequency distributions of hydroacoustically detected fish in 556 Lake Neusiedl (1997 survey) using MUR = 10 and $20 \mathrm{~m}$. Data from cruises 1.1, 1.2 and 1.3 were 557 pooled.

558

559

Fig. 12. Scheme of $3 \mathrm{~dB}$ beam pattern (red line) within the water column for transducer depth 560 $0.35 \mathrm{~m}$ with $1^{\circ}$ downward tilt. Black solid line is the bottom. Red dashed line is the portion of 561 the beam used for analyses with MUR $=10 \mathrm{~m}$. Green dashed areas are regions close to the 562 boundaries which should be avoided when aiming the transducer. 


\begin{tabular}{|c|c|c|c|}
\hline Study site & Transducer depth (m) & Transducer tilt $\left({ }^{\circ}\right.$ downwards $)$ & Target depth $(\mathrm{m})$ \\
\hline \multirow{7}{*}{ 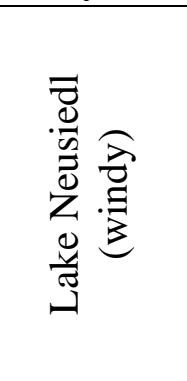 } & \multirow{5}{*}{0.35} & \multirow{5}{*}{1} & 0.15 \\
\hline & & & 0.25 \\
\hline & & & 0.35 \\
\hline & & & 0.5 \\
\hline & & & 0.65 \\
\hline & \multirow{2}{*}{0.5} & 1 & \multirow{2}{*}{0.85} \\
\hline & & 2 & \\
\hline \multirow{18}{*}{ 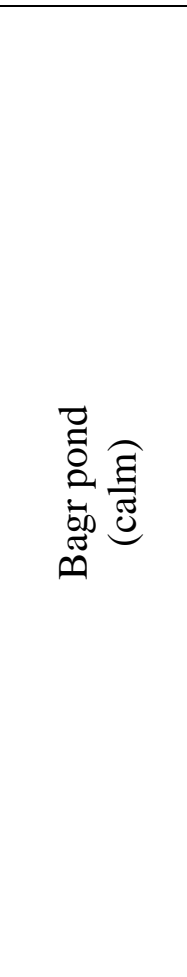 } & \multirow{7}{*}{0.35} & \multirow{7}{*}{1} & 0.15 \\
\hline & & & 0.25 \\
\hline & & & 0.35 \\
\hline & & & 0.50 \\
\hline & & & 0.65 \\
\hline & & & 0.85 \\
\hline & & & 1.05 \\
\hline & \multirow{11}{*}{0.5} & \multirow{6}{*}{0} & 0.15 \\
\hline & & & 0.25 \\
\hline & & & 0.35 \\
\hline & & & 0.50 \\
\hline & & & 0.70 \\
\hline & & & 1.35 \\
\hline & & \multirow{4}{*}{1} & 0.25 \\
\hline & & & 0.5 \\
\hline & & & 0.7 \\
\hline & & & 0.85 \\
\hline & & 2 & 0.85 \\
\hline
\end{tabular}

Table 1

565 The main experimental parameters at the two sites. The bold values of transducer depth and tilt 566 angle were used in the 1997 survey of Lake Neusiedl, subsequently reanalyzed.

567 


\begin{tabular}{|c|c|c|c|c|c|c|c|}
\hline $\begin{array}{l}\text { Study } \\
\text { site }\end{array}$ & $\mathrm{J}$ & $\begin{array}{c}\text { Target } \\
\text { depth }(\mathrm{m})\end{array}$ & $\mathrm{a}$ & $\mathrm{b}$ & $\mathrm{c}$ & d & $r^{2}$ \\
\hline \multirow{5}{*}{ 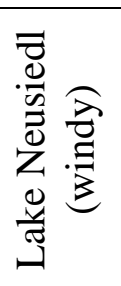 } & 1 & 0.15 & 0.0482 & -0.9239 & 5.8450 & -11.8310 & 0.55 \\
\hline & 2 & 0.25 & 0.0244 & -0.3611 & 2.0379 & -3.2789 & 0.48 \\
\hline & 3 & 0.35 & 0.0130 & -0.1869 & 0.9085 & 0.2503 & 0.19 \\
\hline & 4 & 0.50 & 0.0083 & -0.1425 & 0.8514 & 0.0609 & 0.18 \\
\hline & 5 & 0.65 & 0.0429 & -0.8415 & 5.3269 & -9.1857 & 0.42 \\
\hline \multirow{7}{*}{ 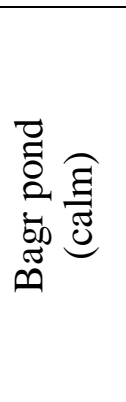 } & 6 & 0.15 & -0.0041 & 0.2327 & -2.7972 & 9.2490 & 0.58 \\
\hline & 7 & 0.25 & -0.0119 & 0.2677 & -1.4779 & 2.9914 & 0.36 \\
\hline & 8 & 0.35 & -0.0039 & 0.1350 & -1.0517 & 3.0830 & 0.41 \\
\hline & 9 & 0.50 & 0.0039 & -0.0926 & 0.7379 & -0.6514 & 0.52 \\
\hline & 10 & 0.65 & 0.0046 & -0.1145 & -0.1426 & 0.9734 & 0.26 \\
\hline & 11 & 0.85 & -0.0016 & 0.0809 & -0.9519 & 4.1513 & 0.27 \\
\hline & 12 & 1.05 & 0.0055 & -0.1598 & 1.7558 & -6.3202 & 0.19 \\
\hline
\end{tabular}

568

569 Table 2

570 Regression analyses of $\sigma_{e r r, j}$ by range according to Eq. (5) for both study sites. $\mathrm{r}^{2}$ is coefficient 571 of determination. The transducer was placed at the depth of $0.35 \mathrm{~m}$ and tilted $1^{\circ}$ down.

572 


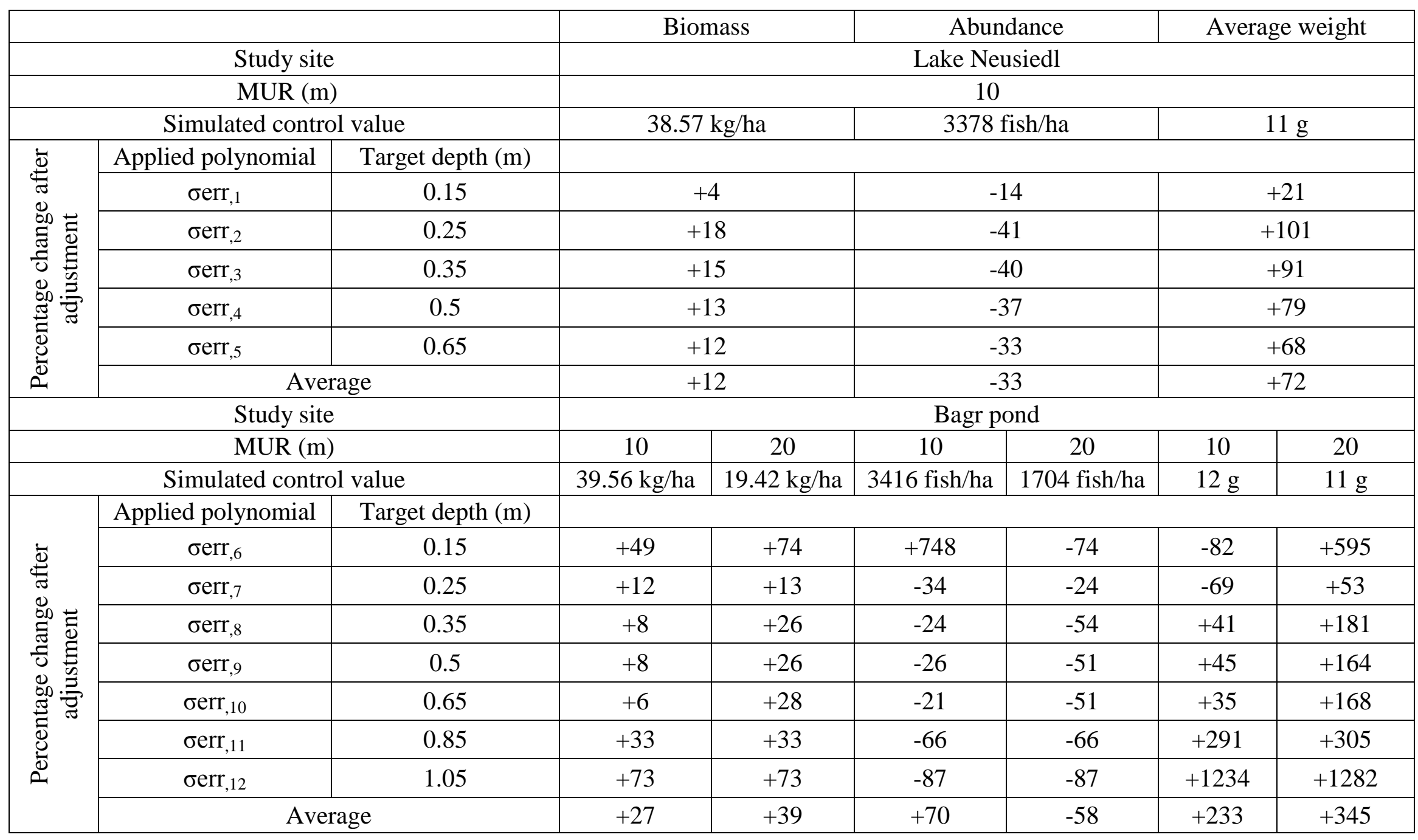

Table 3

Simulated values of fish biomass ( $\mathrm{kg} / \mathrm{ha}$ ), abundance (a number of fish per ha (fish/ha)) and average weight ( $\mathrm{g}$ ) and percentage change after adjustment. 


\begin{tabular}{|c|c|c|c|c|c|c|}
\hline & \multicolumn{2}{|c|}{ Cruise 1.1 } & \multicolumn{2}{c|}{ Cruise 1.2 } & \multicolumn{2}{c|}{ Cruise 1.3 } \\
\hline MUR(m) & 10 & 20 & 10 & 20 & 10 & 20 \\
\hline Biomass (kg/ha), Eq. 13 & 38.8 & 48.1 & 38.5 & 51.6 & 13.7 & 73.2 \\
\hline Abundance (fish/ha), Eq. 11 & 418 & 384 & 1864 & 723 & 384 & 1122 \\
\hline Average weight (g), Eq. 4 and 12 & 138.4 & 200.4 & 28.5 & 70.1 & 41.9 & 156.4 \\
\hline $\mathrm{S}_{\mathrm{V}}(\mathrm{dB})$, Eq. 7 & -55.7 & -54.3 & -54.3 & -53.8 & -56.0 & -50.3 \\
\hline
\end{tabular}

Table 4

Comparisons of biomass, abundance, average weight and $S_{\mathrm{V}}$ from Lake Neusiedl (1997 survey) processed with MURs up to $20 \mathrm{~m}$ and limited to $10 \mathrm{~m}$. 


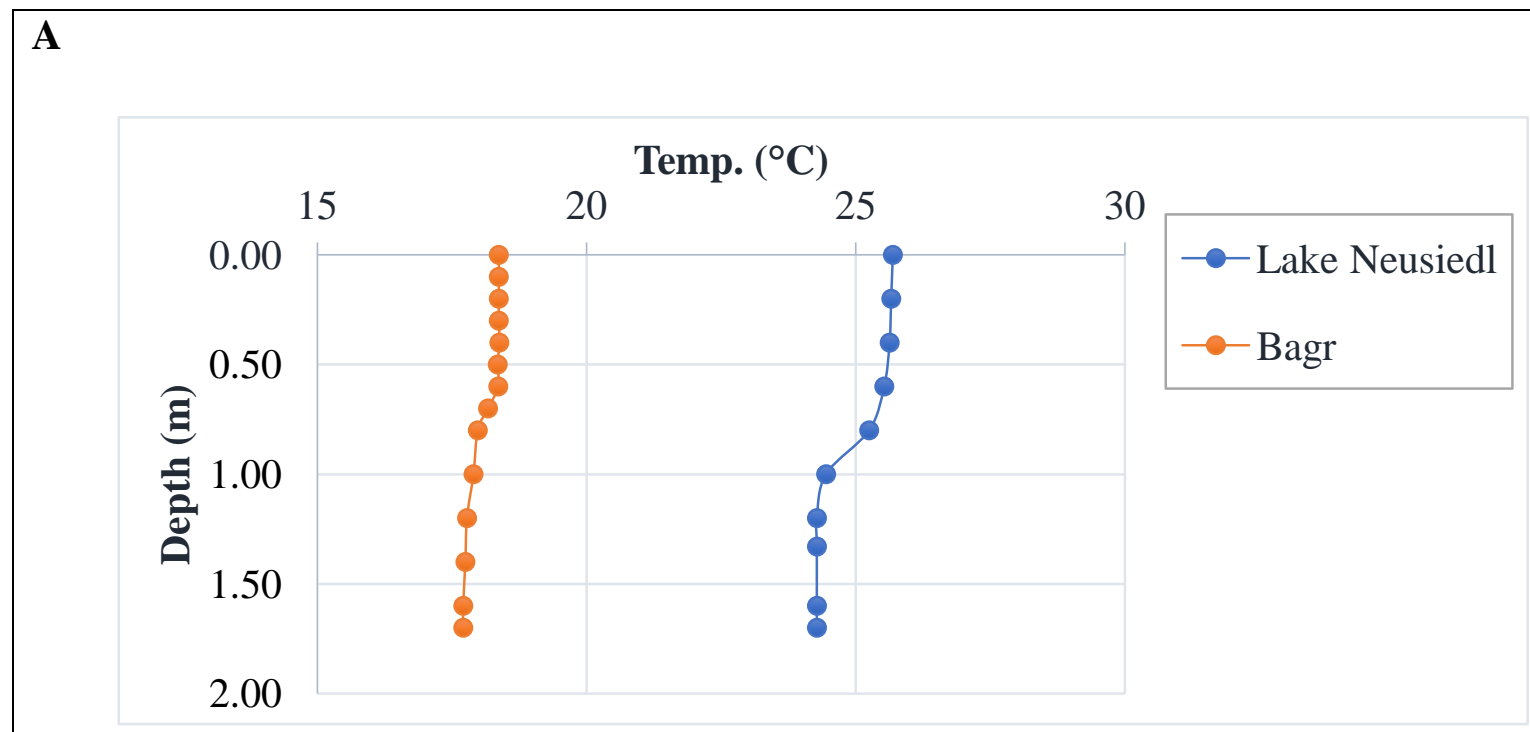

B
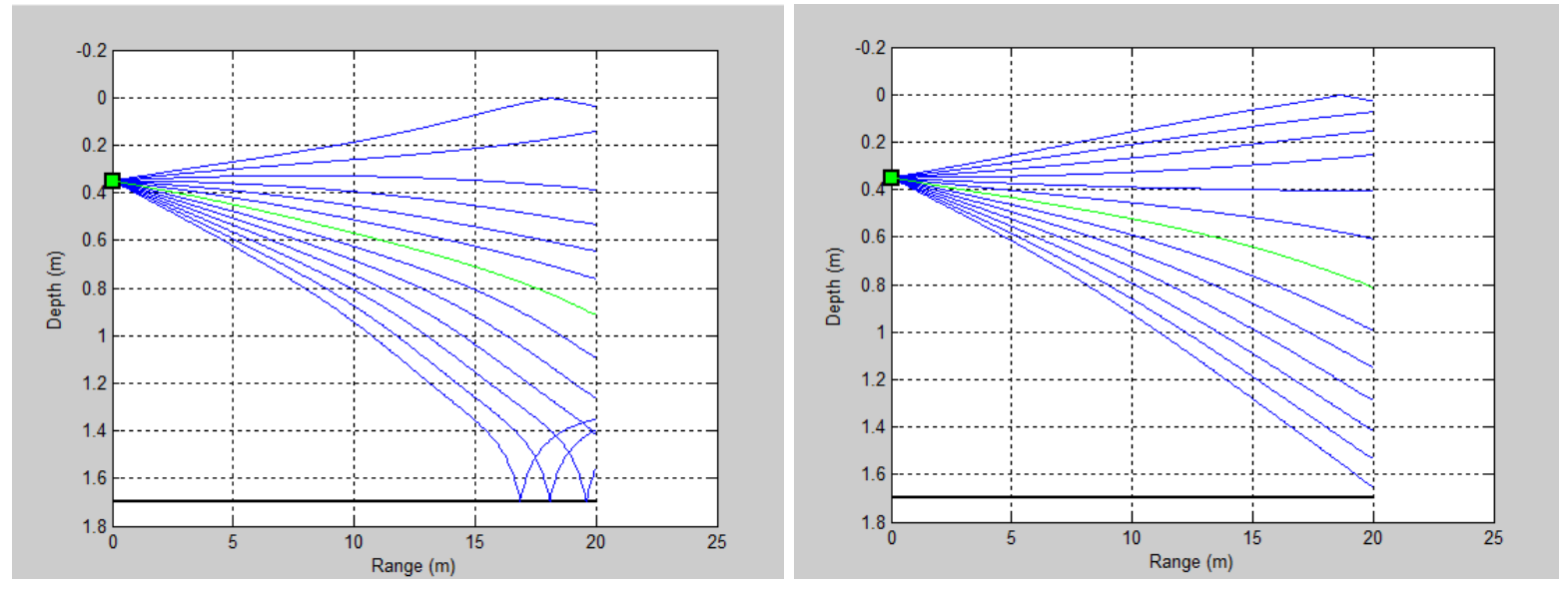

C
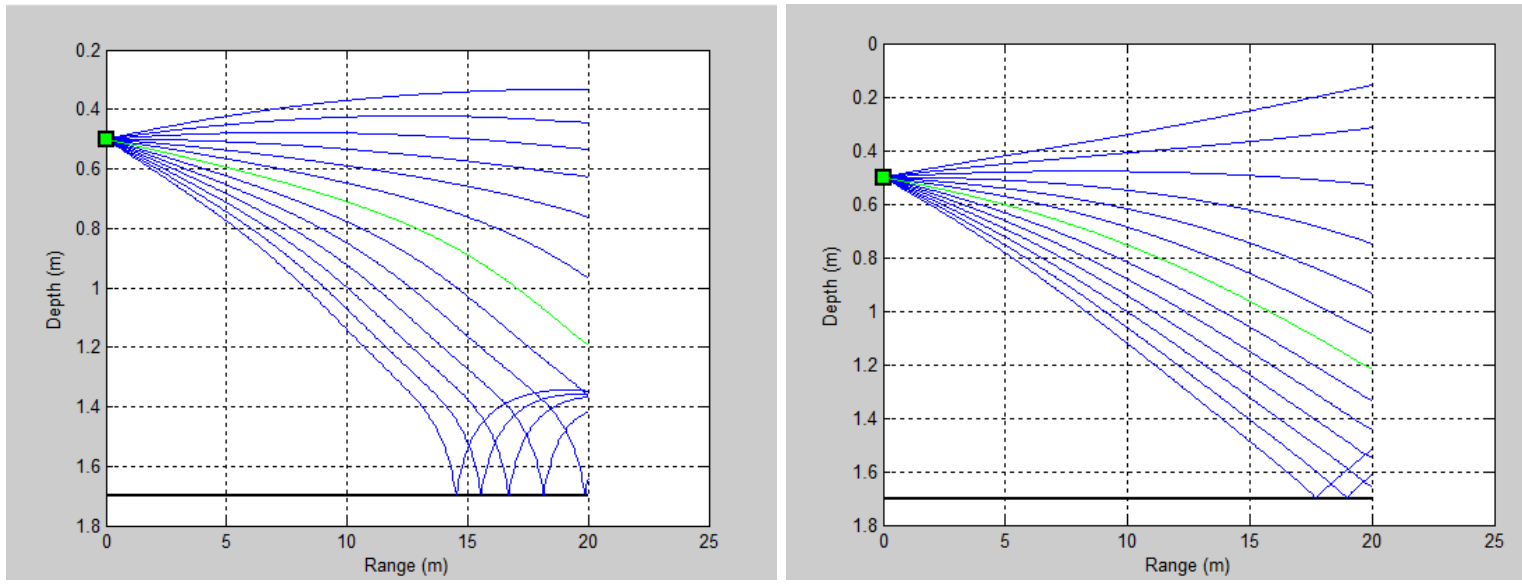

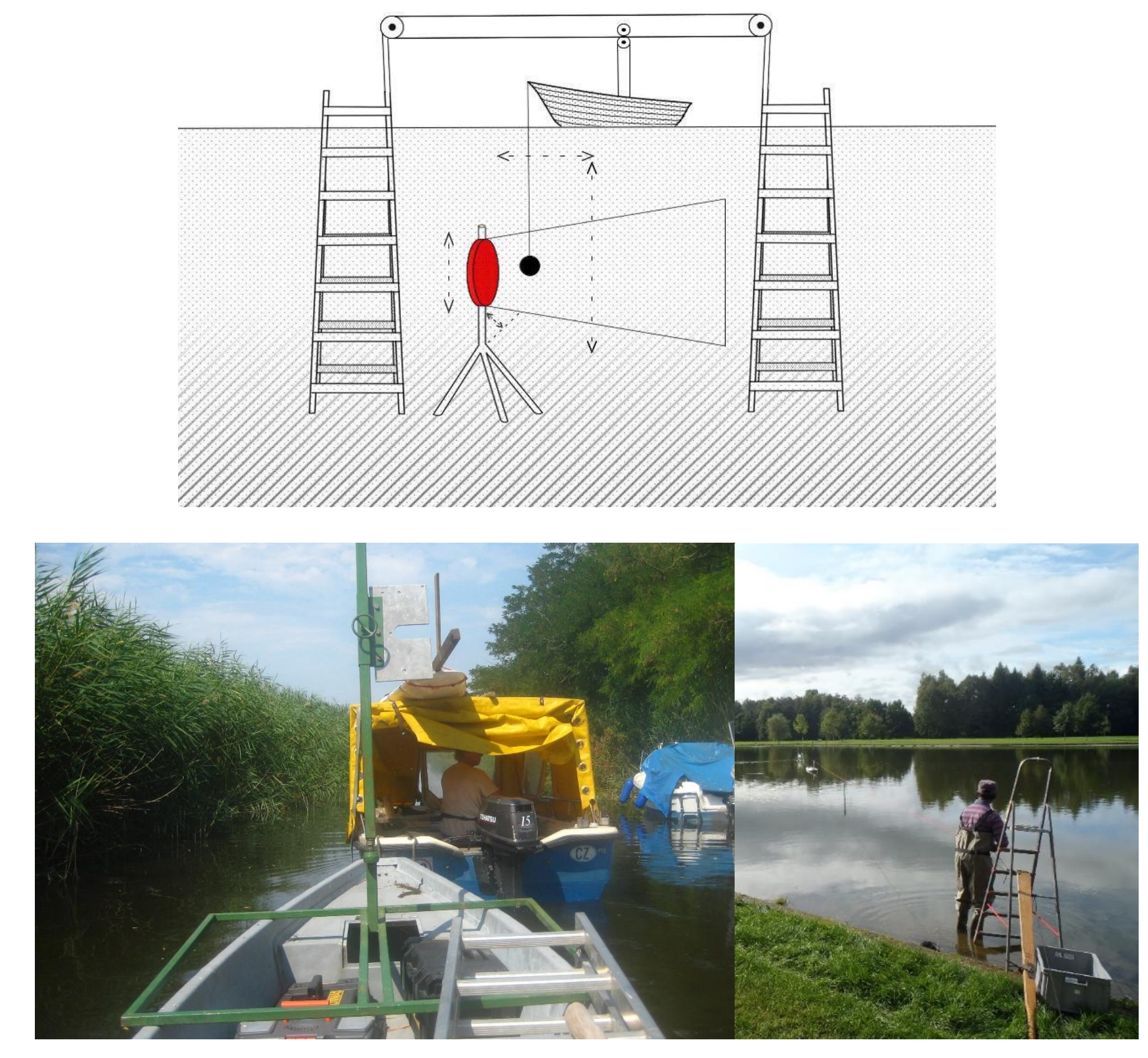

Figure 2
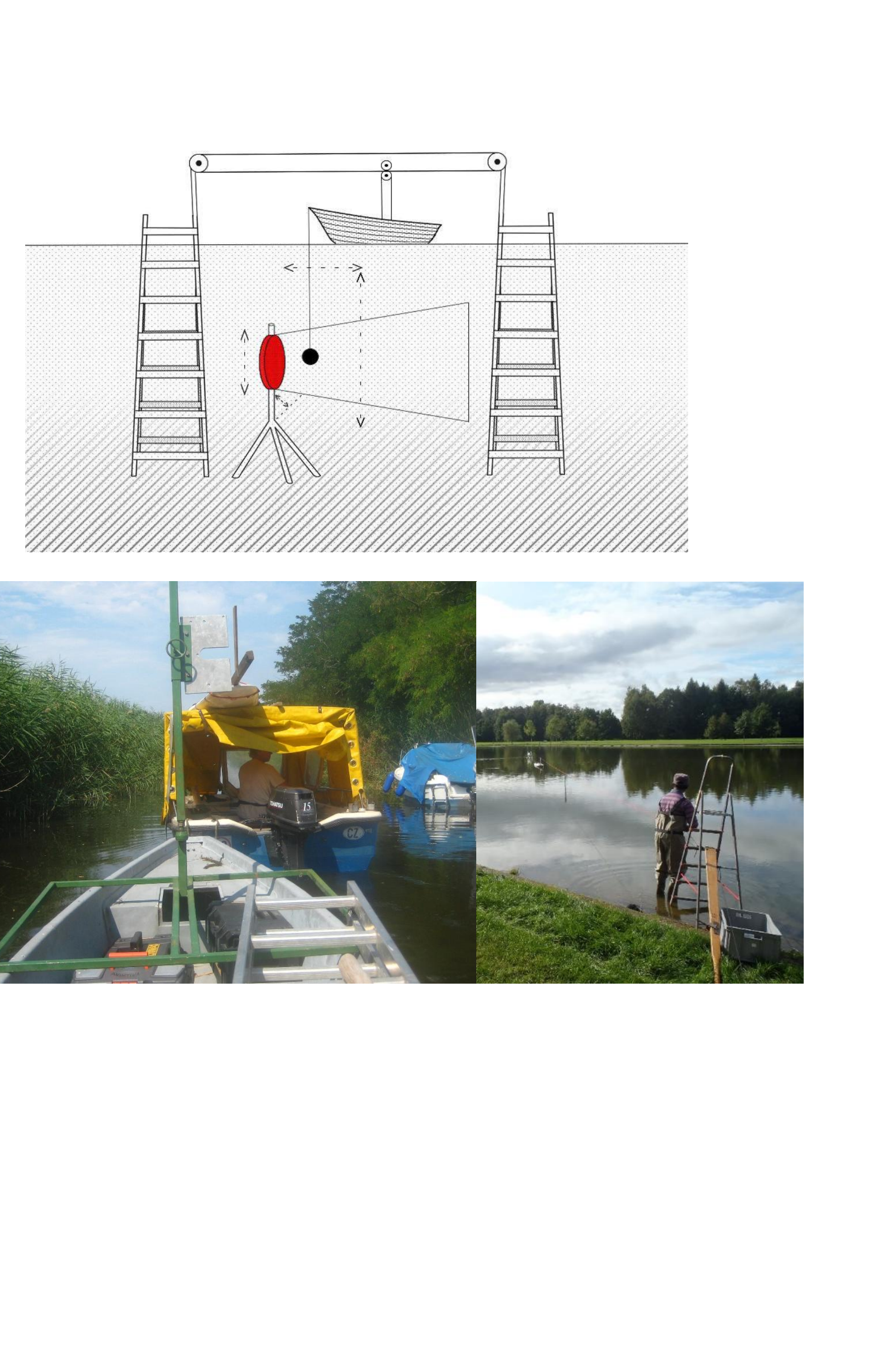

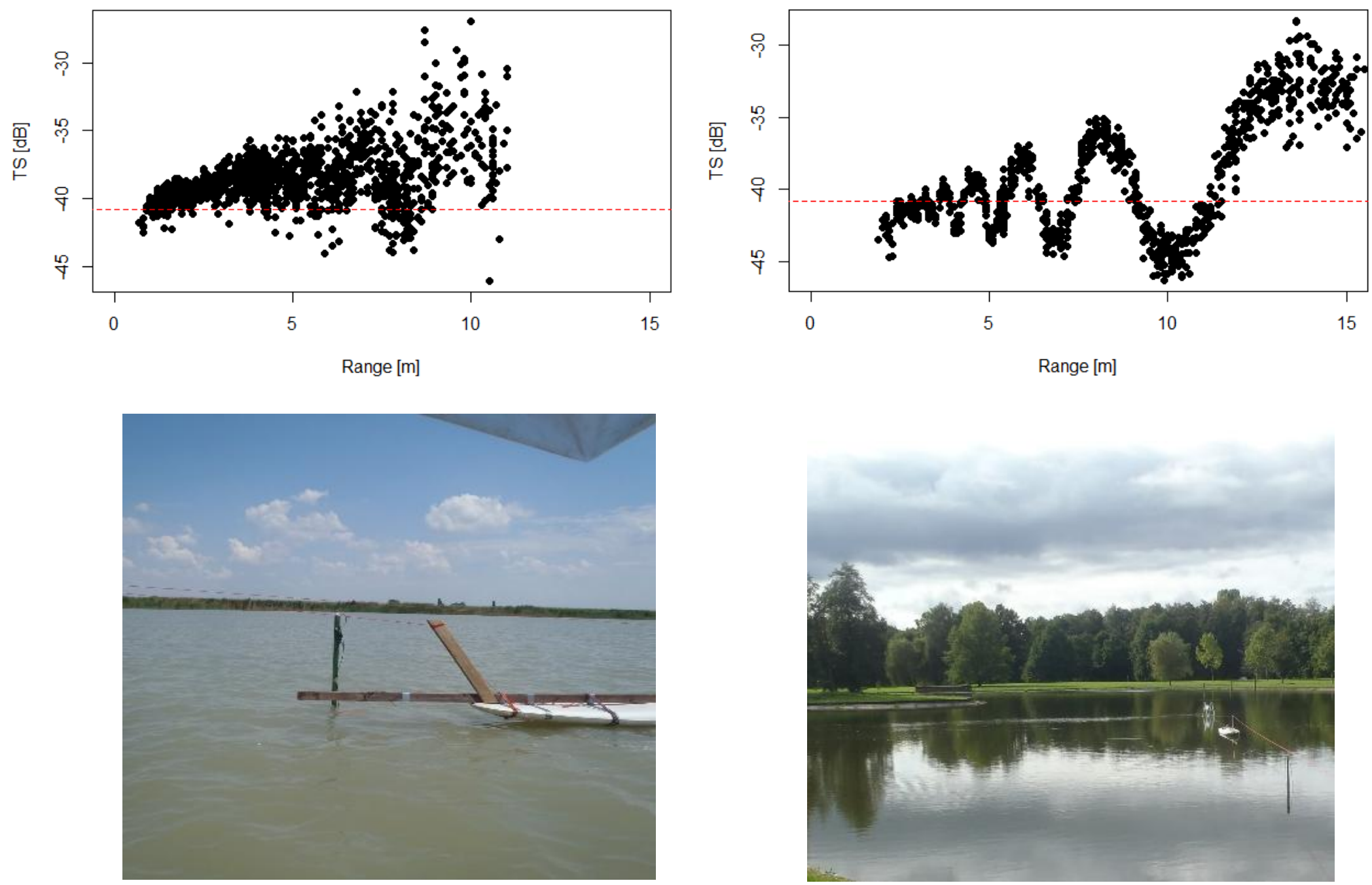

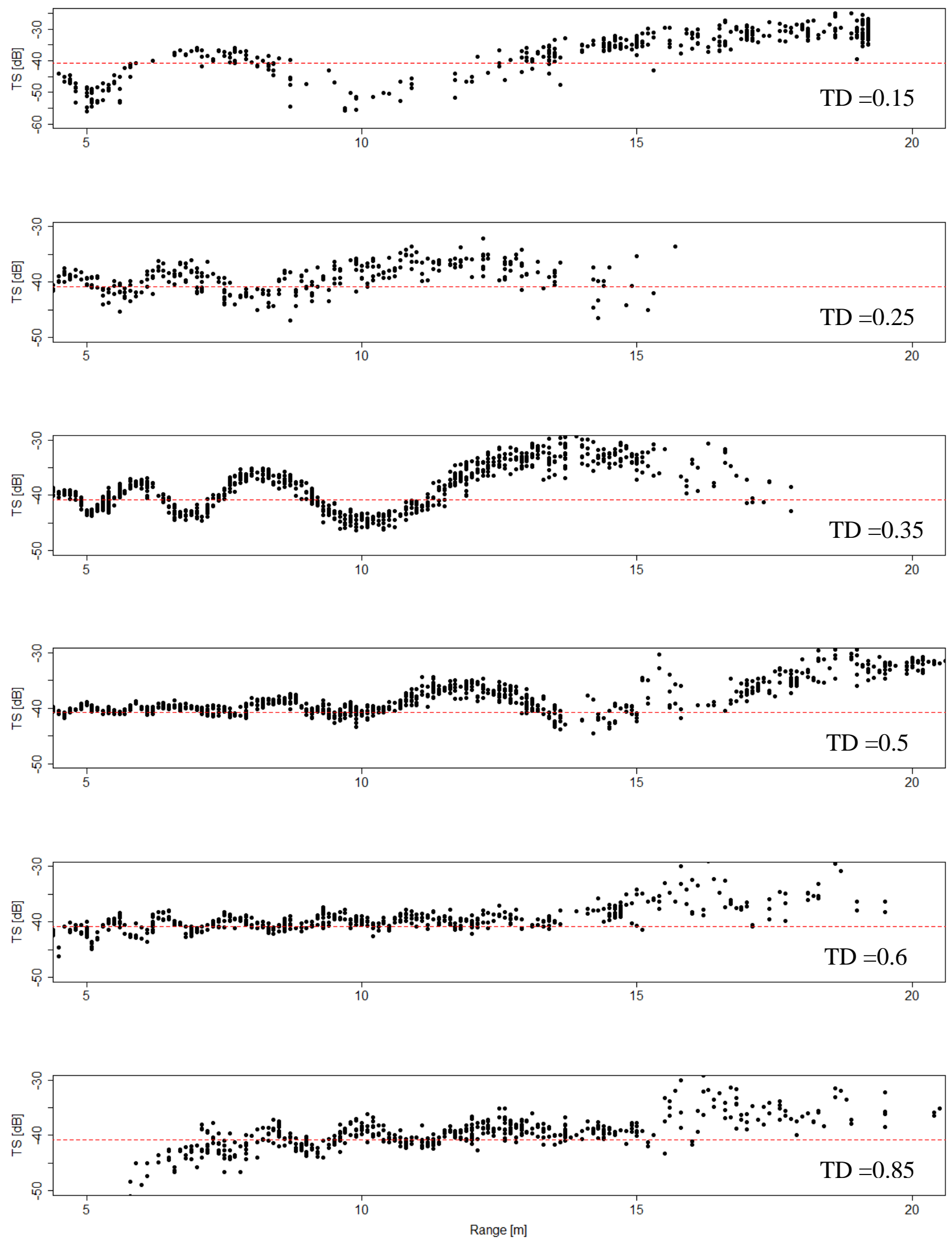


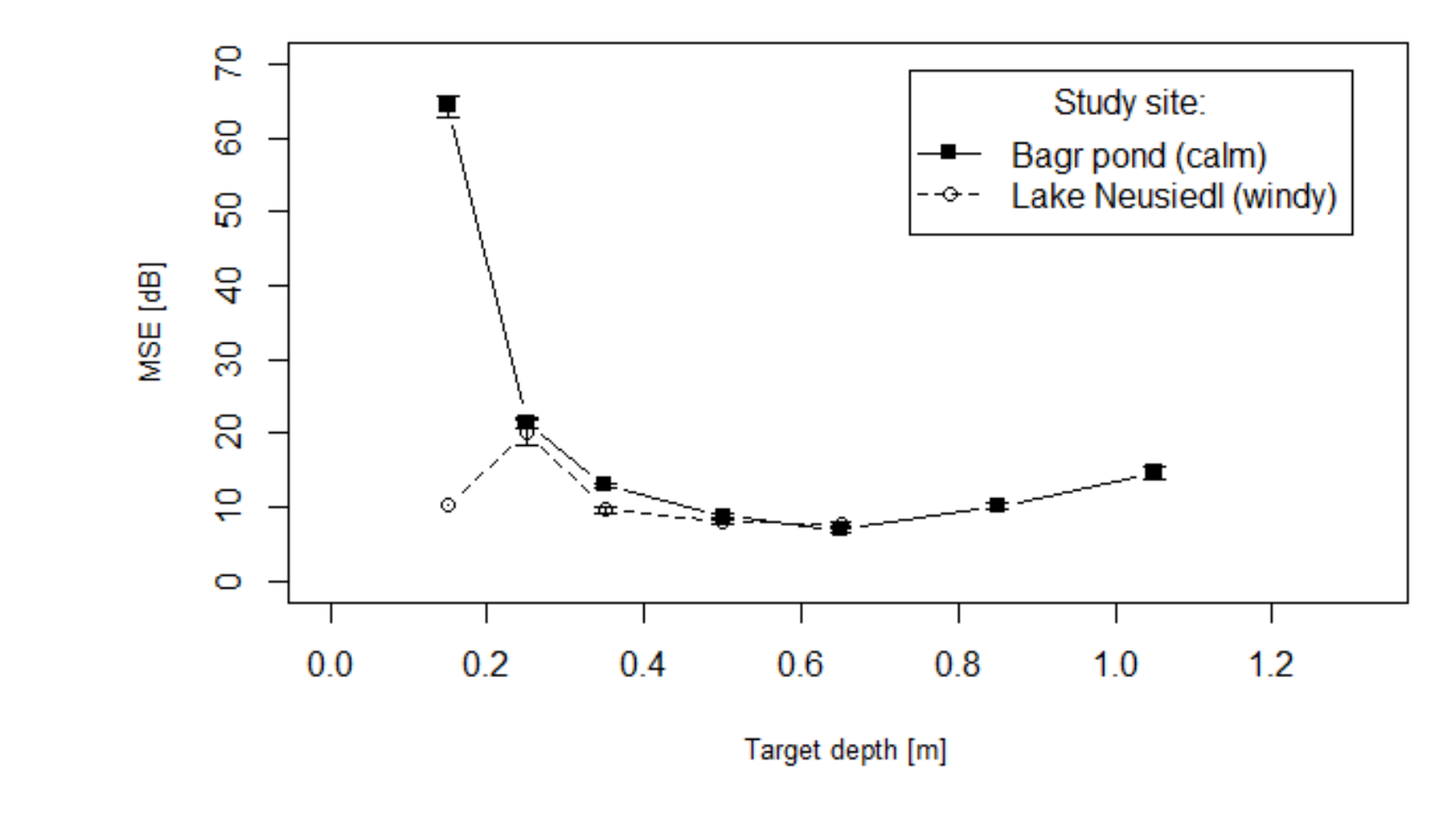

Figure 5

Target depth [m]

\section{5}

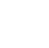

-

(2)

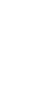
(n)
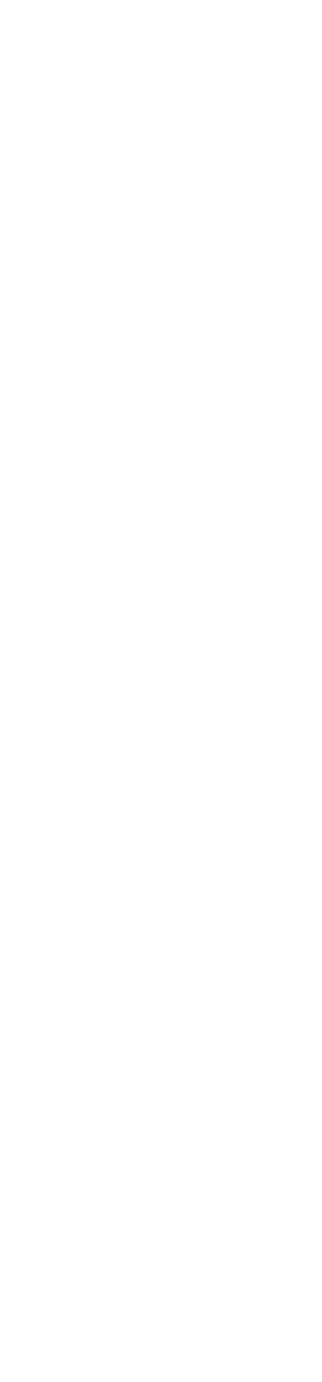

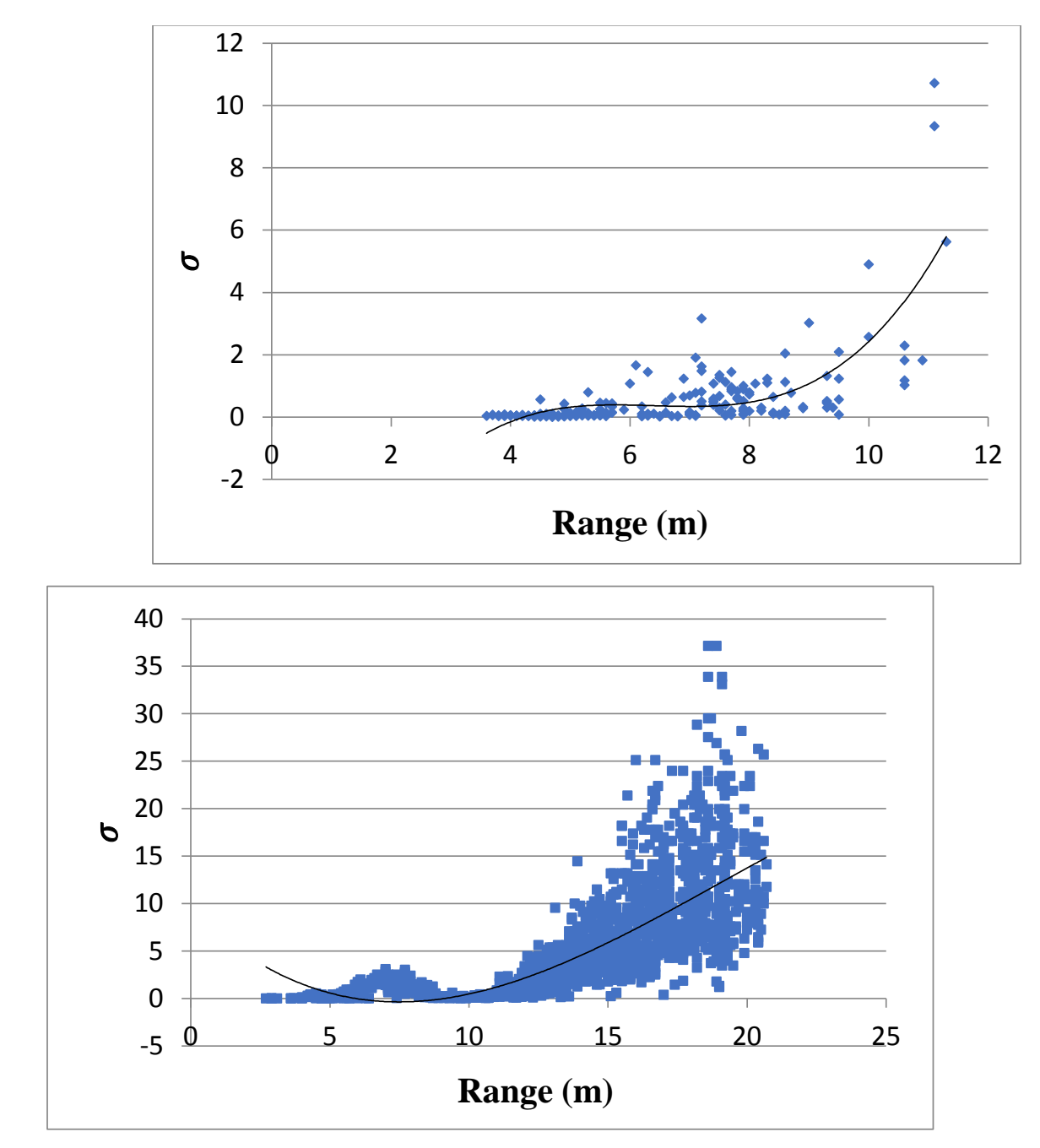

Figure

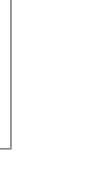
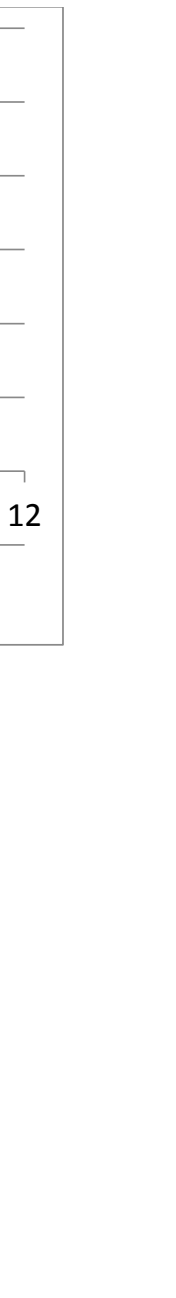
Figure 7

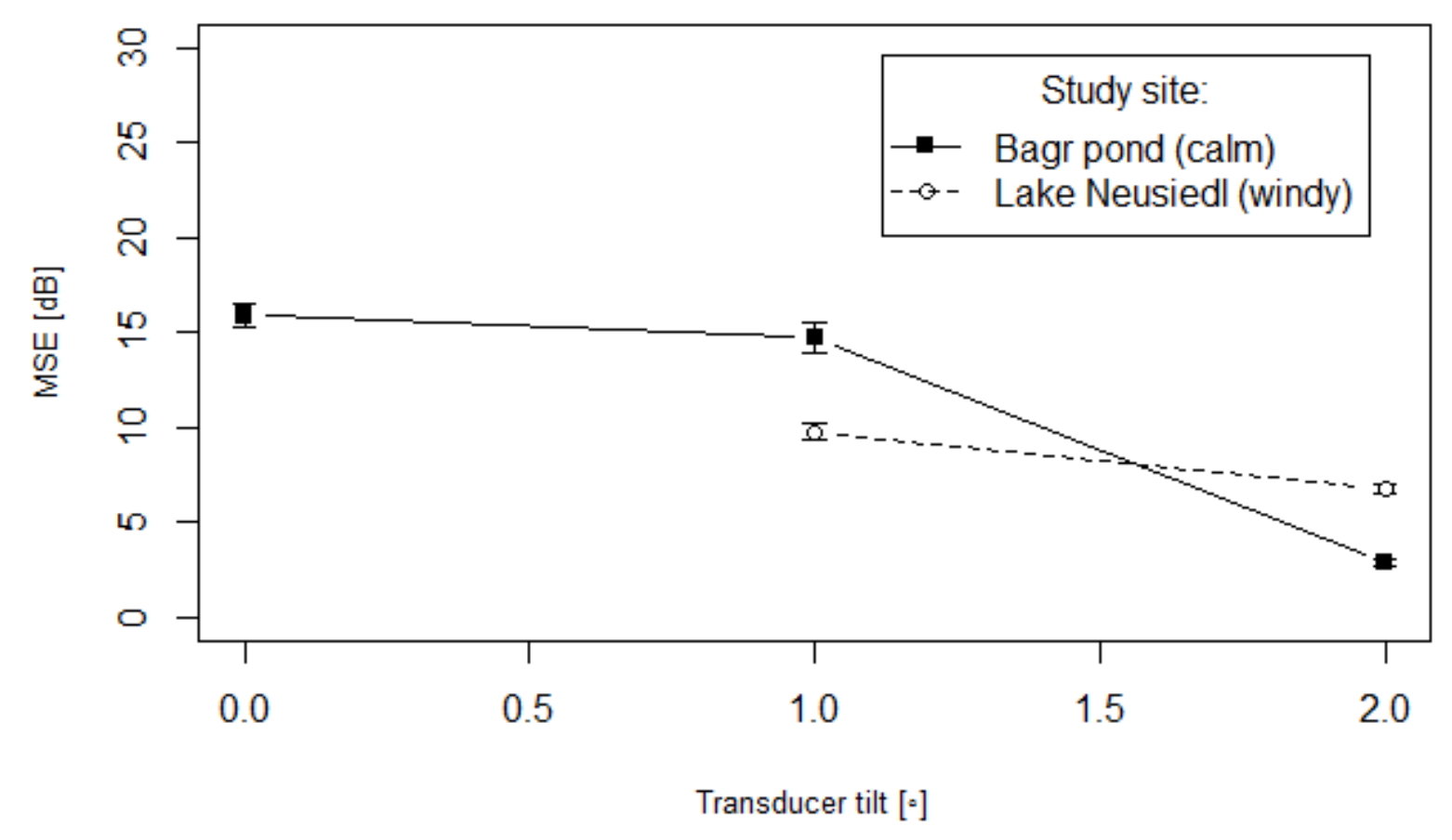

Transducer tilt $\left[^{\circ}\right]$

\section{Figure 7}

.
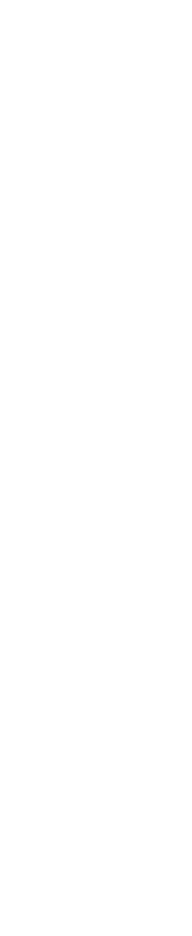

.




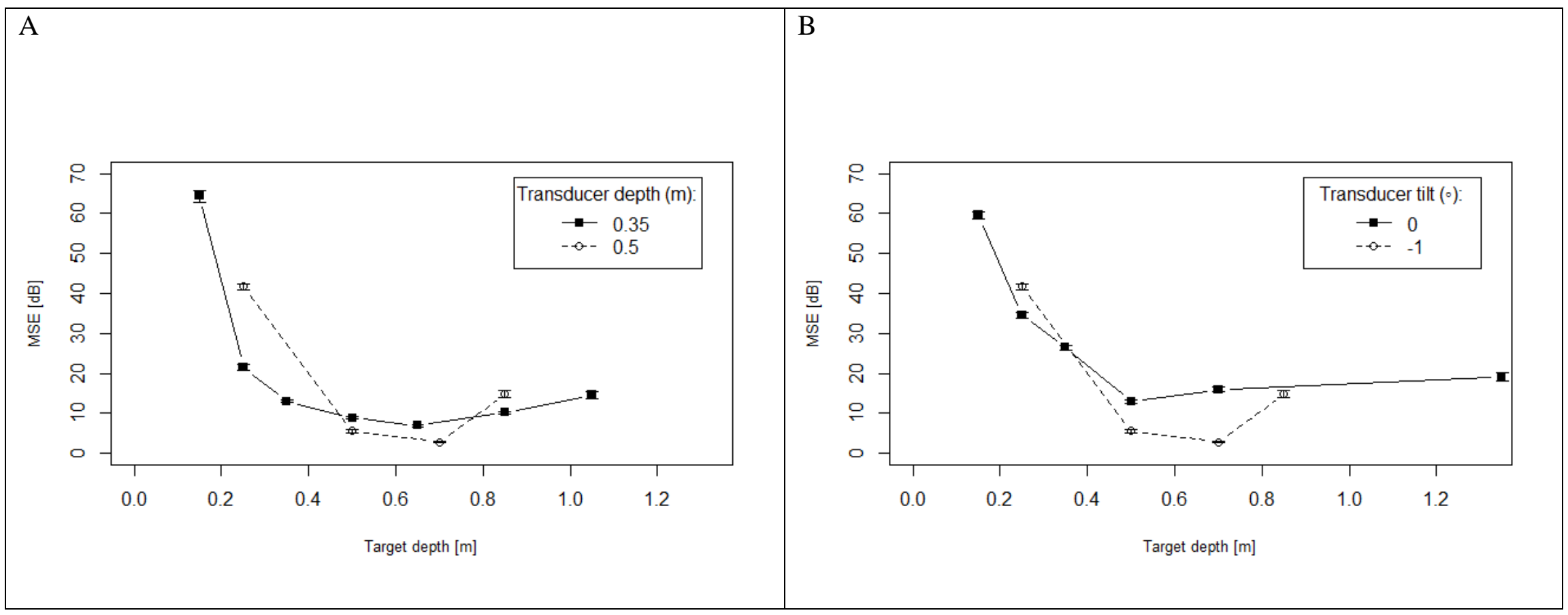


Figure 9

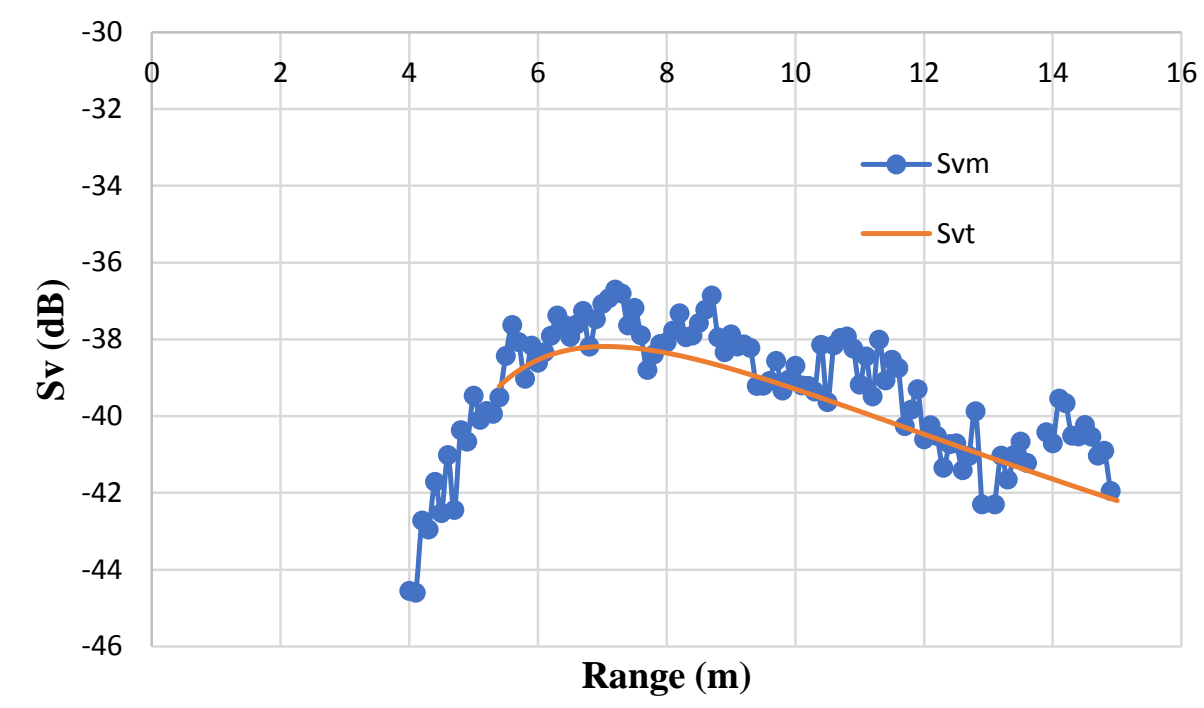

(

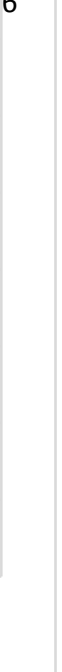




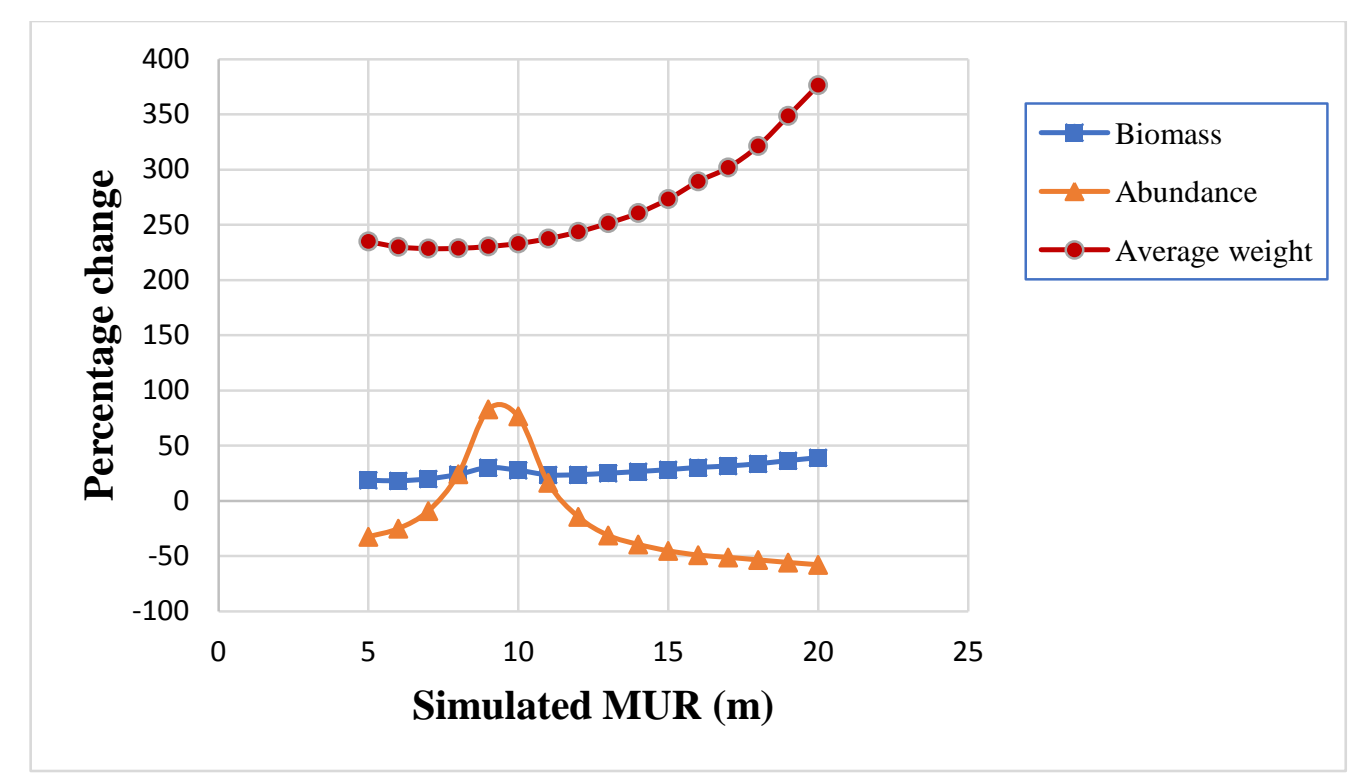

Figure 10 
Figure 11

$$
25
$$

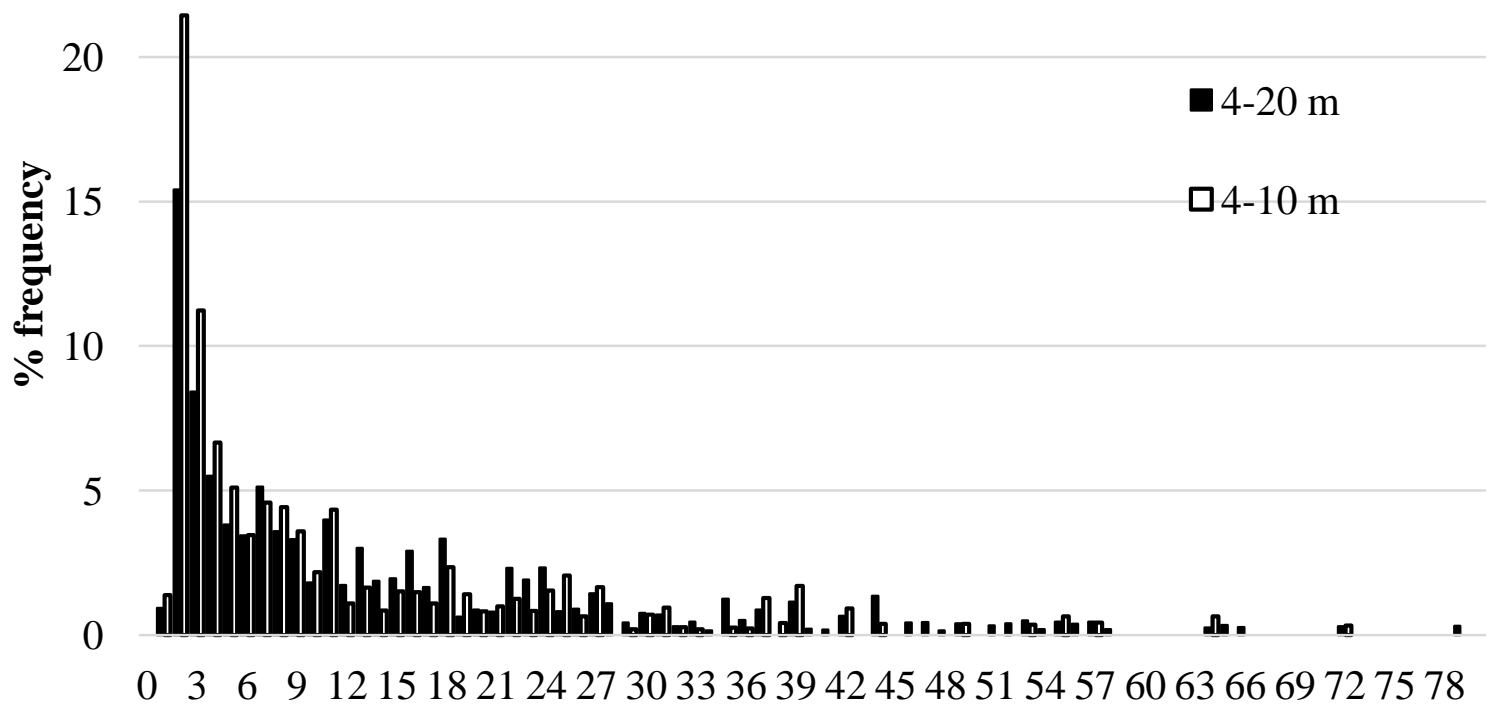
Fish standard length (cm) 
Figure 12

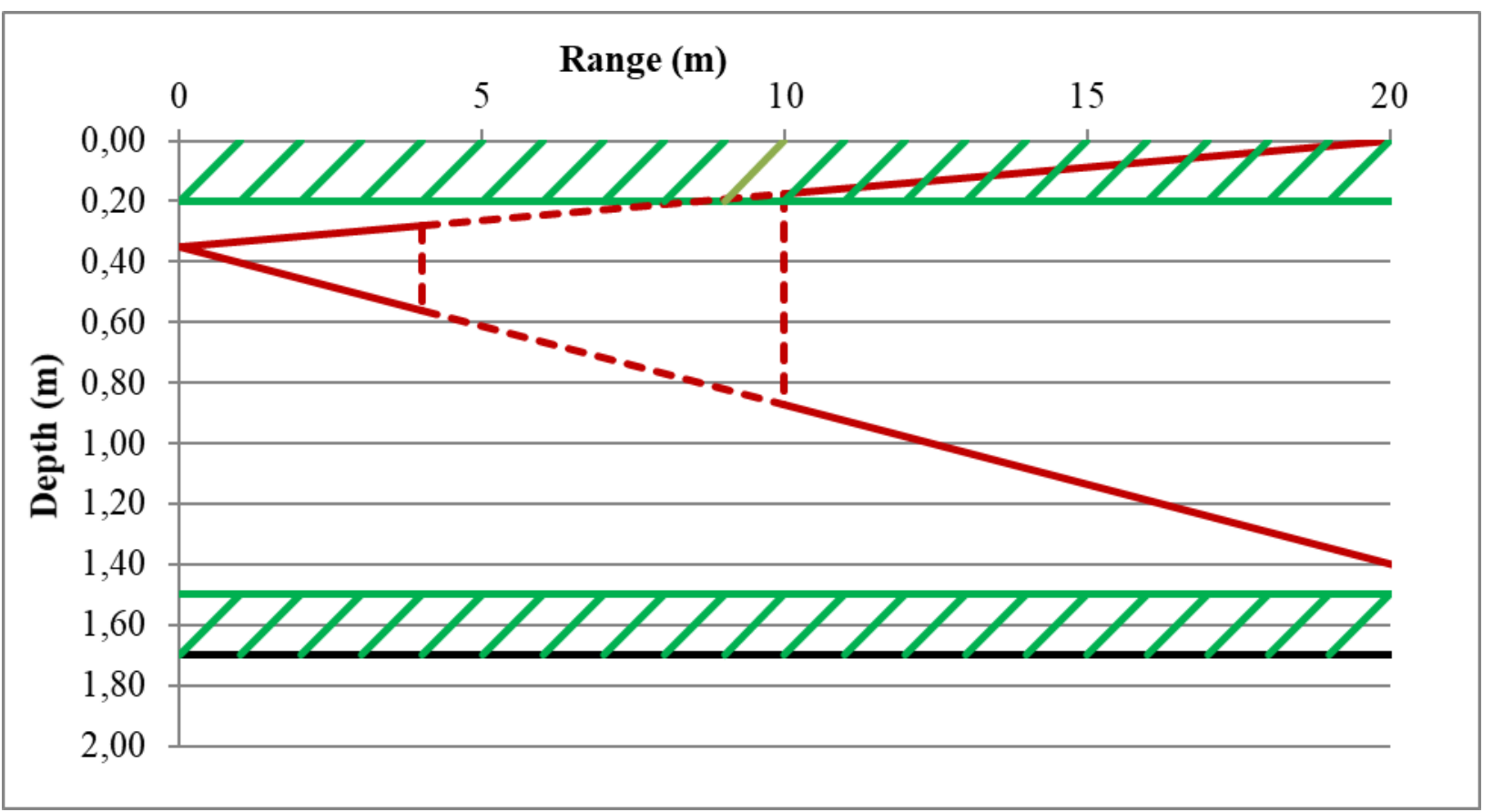

